\title{
The Potential of Diamond and SiC Electronic Devices for Microwave and Millimeter-Wave Power Applications
}

\author{
ROBERT J. TREW, FELLOW, IEEE, JING-BANG YAN, MEMBER, IEEE, AND \\ PHILIP M. MOCK, MEMBER, IEEE
}

Invited Paper

There is significant interest in developing microelectronic devices for blue emission, high temperature, high power, high frequency, and radiation hard applications. This interest has generated significant research effort in wide bandgap semiconductor material, in particular SiC and semiconducting diamond. Both of these materials are similar in crystal structure with half of the carbon atoms in the diamond structure replaced by Si to produce SiC. However, the latter material exists in a host of polytypes, the causes of which are not completely understood. The deposition of monocrystalline diamond at or below 1 atm total pressure at $T<1000^{\circ} \mathrm{C}$ has been achieved on diamond substrates, although deposited film has been polycrystalline on all other substrates. For significant application to electronic devices, the heteroepitaxy of single crystal films of diamond and an understanding of mechanisms of nucleation and growth, methods of impurity introduction and activation, and further device development must be achieved. The technology of producing SiC is more advanced and the deposition of thin films and the associated technologies of impurity incorporation, etching, and electrical contacts have culminated in a host of solid-state devices. In this paper, the potential of $\mathrm{SiC}$ and diamond for producing microwave and millimeter-wave electronic devices is reviewed. Both of these materials have been proposed for fabrication of devices capable of producing $R F$ output power significantly greater than can be achieved with comparable devices fabricated from commonly used semiconductors such as $S i$ and GaAs. Theoretical calculations are presented of the $R F$ performance potential of several candidate high frequency device structures: the MEtal Semiconductor Field-Effect Transistor (MESFET), the IMPact Avalanche Transit-Time (IMPATT) diode, and the Bipolar Junction Transistor (BJT).

\section{INTRODUCTION}

The utilization of semiconducting $\mathrm{SiC}$ and diamond for high frequency electronic devices has been of interest to device physicists for many years. For example, the

Manuscript received October 25, 1990; revised January 14, 1991. This work was supported by the SDIO/ONR under Contracts N00014-86K0666, N00014-90-J-1604, and N00014-88-K0341.

The authors are with the Electrical and Computer Engineering Department, North Carolina State University, Raleigh, NC 27695-7911. electronic properties of diamond were investigated in the 1930's [1] and serious work with $\mathrm{SiC}$ dates at least to the early 1960 's. Some of the initial interest in these materials was for high temperature, corrosion resistant semiconductors. As the material parameters became better known it became apparent that these materials possess a combination of parameters that, in many respects, make them ideal for various applications, including high frequency devices. Diamond has been proposed for use as detectors (radiation and ultraviolet photodetectors), power and microwave devices (bipolar, field-effect, and permeable base transistors, IMPATT diodes), green-blue LED's, thermistors, and switching devices. Devices that can be fabricated from $\mathrm{SiC}$ include LED's, thermistors, MESFET's, bipolar and heterojunction transistors, and various types of diodes.

The early attempts to utilize these materials were hindered by technological problems related to crystal growth and purity and to the development of suitable ohmic and rectifying contacts. Although rapid progress has been made in recent years on solutions to these problems, growth and device fabrication technology is still primitive compared to $\mathrm{Si}$ and $\mathrm{GaAs}$ and the necessary technology has not yet developed to the point where high performance devices can be easily fabricated. At the current state-of-the-art, $\mathrm{SiC}$ technology is more advanced than that for diamond and electronic devices are being reported. Preliminary work has also been reported on diamond devices using both natural and synthetic crystals.

In this paper, the potential of $\mathrm{SiC}$ and diamond for producing high performance microwave and millimeterwave electronic devices is investigated. It is shown that both of these materials possess characteristics that may permit RF electronic devices with performance similar to or greater than what is available from devices fabricated from the conventional semiconductors, Si, GaAs, and InP. 
The investigation makes use of theoretical computer simulations of the MEtal Semiconductor Field-Effect Transistor (MESFET) and the IMPact Avalanche Transit-Time (IMPATT) diode. Bipolar Junction Transistor (BJT) operation is also investigated by means of a large signal microwave equivalent circuit model. These devices represent some of the most commonly used electronic devices for microwave and millimeter-wave applications and also, the most likely devices to be suitable for fabrication from the wide bandgap semiconductors. Of these, the MESFET is of particular interest since it is structurally a simple device and readily fabricated in a variety of semiconductor materials. The MESFET can be operated over a wide frequency range extending from the low megahertz $(\mathrm{MHz})$ region to well into the millimeter-wave bands (i.e., well over $100 \mathrm{GHz}$ ). The IMPATT diode can also have a relatively simple structure and is attractive for high frequency applications. IMPATT devices fabricated from $\mathrm{GaAs}$ and $\mathrm{Si}$ have operated as high as $250 \mathrm{GHz}$ and $430 \mathrm{GHz}$, respectively. The BJT has a relatively complex structure and high performance devices will most likely be difficult to fabricate in wide bandgap semiconductors. In particular, technological and material problems will likely limit the high frequency performance of these devices to the low microwave region. However, BJT's fabricated from wide bandgap semiconductors are attractive candidates for low frequency (UHF and below) power applications.

The accuracy of the theoretical calculations is dependent upon the values used for the material parameters required in the device models. For extensively used semiconductors such as $\mathrm{Si}$ and $\mathrm{GaAs}$, these parameters have been studied using a variety of experimental and theoretical techniques. For SiC and especially for diamond, however, the material parameters are not well known. Semiconducting diamond has not yet been well characterized due to significant difficulties in producing device quality material. Suitable techniques for introducing donor impurities with reasonable activation properties to create n-type semiconducting layers in diamond are not currently known. Boron can be introduced into diamond to produce p-type epitaxial layers. However, the relatively high activation energy of boron acceptors may require high temperature operation (e.g., $500^{\circ} \mathrm{C}-600^{\circ} \mathrm{C}$ ) to obtain appropriate charge densities. Since hole transport rapidly degrades with temperature, demonstrating approximately a $T^{-2.8}$ temperature sensitivity, it may prove difficult to fabricate high performance p-type microwave devices.

The material data used in this work was obtained from published reports and from discussions with various researchers. Although uncertainty exists in specific parameter values an attempt was made to select reasonable values for use in device applications. The diamond device calculations assume the existence of activated $\mathrm{n}$-type semiconducting epitaxial layers. Although such crystals do not presently exist, the available data indicates that $n$-type material would produce the highest performance devices. Future research may result in the availability of suitable device quality material.

\section{BACKGROUND}

\section{A. $\mathrm{SiC}$}

Silicon carbide is the only compound in the $\mathrm{SiC}$ system that exists in the solid state, but it can occur in many polytype structures [2], [3]. More than 170 polytypes have been identified. The lone cubic polytype crystallizes in the zincblende structure and is denoted as $3 \mathrm{C}$ - or $\beta$-SiC. The additional hexagonal $(\mathrm{H})$ and rhombohedral $(\mathrm{R})$ polytypes are collectively referred to as $\alpha-\mathrm{SiC}$. The most common polytypes are $3 \mathrm{C}$ and $6 \mathrm{H}$; however, $4 \mathrm{H}, 15 \mathrm{R}$, and $2 \mathrm{H}$ have also been identified in crystalline form, but are rare. Most of the polytypes are extremely stable, except that $2 \mathrm{H}$ is unstable and can transform to other polytypes at temperatures as low as $400^{\circ} \mathrm{C}$. The most stable polytype is $6 \mathrm{H}-\mathrm{SiC}[4]$.

Silicon carbide does not exist in significant quantities in nature. The first reported synthesis was accidental: the result of attempts by Berzelius to make diamond. The development of the Acheson process [5] in 1891 brought $\mathrm{SiC}$ production to commercial scale in the abrasives industry. Initial $\mathrm{SiC}$ research was generally conducted using crystals that were occasional by-products of this process. In 1955 , Lely [6] developed a laboratory version of the industrial sublimation process and was able to produce rather pure $\alpha$ $\mathrm{SiC}$ single crystals. Due to the growth temperature of about $2500^{\circ} \mathrm{C}$, only $\alpha$-SiC polytypes were produced in the Lely process. Growth of $\beta$-SiC was sometimes observed during the cool down phase. The doping level of the $\mathrm{SiC}$ crystals depends strongly upon the impurity content of the starting material, the quality of the argon atmosphere, as well as temperature and duration of degassing cycles used in this process. The success of the Lely process led to significant research effort directed toward development of $\mathrm{SiC}$ during the 1960's.

The electron transport characteristics of $\beta$-SiC over the temperature range of $27^{\circ} \mathrm{C}-730^{\circ} \mathrm{C}$ are predicted from theoretical calculations to be significantly greater than can be obtained from $\alpha-\mathrm{SiC}$ due to reduced phonon scattering in the cubic material. For this reason, there is significant interest in the growth of thin films of $\beta-\mathrm{SiC}$ for device applications. Epitaxial films of $\beta$-SiC have primarily been grown on chemically converted surfaces of monocrystalline $\mathrm{Si}(100)$ substrates by chemical vapor deposition using the high purity gases of $\mathrm{SiH}_{4}$ entrained in the carrier gas of $\mathrm{H}_{2}$. A review of growth techniques can be found in [7], [8]. Silicon carbide can be doped n- or p-type by diffusion [9], epitaxial growth [10], [11], and ion-implantation [12]-[14]. The diffusion of dopants into $\mathrm{SiC}$ requires temperatures around $1900^{\circ} \mathrm{C}$, and special precautions are necessary to prevent sublimation of the bulk crystal at this temperature. Moreover, this temperature is considerably above the melting point of $\mathrm{SiO}_{2}$, and no commercially attractive alternative diffusion masking material has yet been found. Therefore, doping during epitaxial growth or ion implantation with $\mathrm{B}$ or $\mathrm{Al}$ (p-type) and $\mathrm{P}$ or $\mathrm{N}$ (n-type) is more suitable for $\mathrm{SiC}$ devices. Using epitaxial growth, the dopant gases of $\mathrm{N}_{2}$ (or $\mathrm{NH}_{3}$ ), 
$\mathrm{PH}_{3}, \mathrm{~B}_{2} \mathrm{H}_{6}$, and $\mathrm{AlCl}_{3}$ (or $\mathrm{Al}\left(\mathrm{CH}_{3}\right)_{3}$ carried in $\mathrm{H}_{2}$ ) are incorporated directly into the primary gas stream during chemical vapor deposition. For ion implanted crystals, damaged or amorphous regions are annealed at a temperature between $1400^{\circ} \mathrm{C}$ and $1800^{\circ} \mathrm{C}$ [14]. Unintentionally doped $\beta$-SiC epilayers are usually n-type with electron concentrations and mobilities of $3 \times 10^{16}-3 \times 10^{17} \mathrm{~cm}^{-3}$ and $250-550 \mathrm{~cm}^{2} / \mathrm{V}$-s, respectively [15].

Historically, $\mathrm{SiC}$ can be considered one of the first known semiconductors and electroluminescence was reported by Round [16] in 1907. Blue light-emitting diodes (LED's) have been fabricated by epitaxial deposition of $\mathrm{SiC}$ from carbon-saturated silicon solutions [17]. Bipolar transistors fabricated from material grown by a similar technique have also been reported [11]. MESFET's fabricated from $\alpha$ SiC were first reported by Muench et al. [11], [18] in 1977. In this work, a thin layer of n-type SiC doped with nitrogen to a concentration of about $10^{16} \mathrm{~cm}^{-3}$ was deposited by liquid-phase epitaxy (LPE) on a p-type SiC crystal. The ohmic contacts were formed from an Al-Si alloy and the gate was formed by depositing thin layers of titanium and gold. Current saturation was observed and the maximum transconductance was reported to be 1.75 $\mathrm{mS} / \mathrm{mm}$ for a device with a gate length of $10 \mu \mathrm{m}$. The first $\beta$-SiC MESFET was fabricated by Yoshida et al. [19]. The Al-doped p-type $\beta$-SiC layer was epitaxially grown on a p-type Si substrate, followed by growth of an unintentionally doped n-type layer. The device had high channel resistance and a maximum transconductance of only $90 \mu \mathrm{S} / \mathrm{mm}$ was obtained. Improved devices with transconductances of $1.7 \mathrm{mS} / \mathrm{mm}$ and $0.15 \mathrm{mS} / \mathrm{mm}$ at room temperature and $400^{\circ} \mathrm{C}$ were later reported by the same researchers [20]. MESFET's fabricated from $\beta$-SiC have also been reported by Kong et al. [21] and Kelner et al. [22], [23]. The transconductances for these devices were $1.6 \mathrm{mS} / \mathrm{mm}$ and $2.3 \mathrm{mS} / \mathrm{mm}$, respectively. Junctiongate field-effect transistors [24], [25] and depletion mode MOSFET's have also been fabricated from $\beta$-SiC grown by chemical vapor deposition (CVD) on an $\alpha$-SiC substrate [13], [14]. Recently, an $\alpha$-SiC MESFET with a $1-\mu \mathrm{m}$ gate length demonstrated a maximum room temperature transconductance of $25 \mathrm{mS} / \mathrm{mm}$ and a current gain cutoff frequency $\left(f_{T}\right)$ of about $3 \mathrm{GHz}$ [26]. Although this device has a significantly improved transconductance relative to previously reported devices, it 's performance is still limited by high parasitic resistances. Much improved performance can be expected as improved device fabrication techniques yield lower parasitics.

\section{B. Diamond}

Crystalline carbon usually exists in two structures: diamond (cubic) and graphite (hexagonal). At one atmosphere pressure and room temperature, graphite is stable while diamond is metastable. According to impurity content, diamond is grouped into four distinct types: type $\mathrm{Ia}, \mathrm{Ib}$, IIa, and IIb. Approximately $98 \%$ of natural diamonds have nitrogen aggregates and are referred to as type Ia. Diamonds in this category are usually near colorless and yellow, but they may also be brown or gray. In approximately $0.1 \%$ of natural diamonds and in most of the synthetic diamonds produced under high pressure, nitrogen is present on isolated substitutional lattice sites. This type of diamond is referred to as type $\mathrm{Ib}$ and the diamonds are intrinsically yellow. Diamond containing nitrogen as the major impurity with a low concentration (less than $\sim 10^{18} \mathrm{~cm}^{-3}$ ) is referred to as type IIa and is usually near-colorless. Type IIb diamonds contain boron as the major impurity and are usually blue or gray in color. The diamonds exhibit slightly p-type conductivity at room temperature. Semiconducting diamond is generally type IIb and is extremely rare in nature.

The electronic properties of diamond were investigated in the 1930's [1]. It was found that there were two basic types of diamond according to different optical absorption spectrum. One type was opaque in the infrared and ultraviolet spectrum while the other type was transparent. Little difference in other physical properties was observed between the two types. Natural semiconducting diamond was discovered in 1952 [27]. Custers found that type IIb diamond phosphoresced when excited by far ultraviolet radiation and showed high electrical conductivity, whereas type IIa diamond did not phosphoresce and showed low conductivity. In 1962, General Electric reported synthetic p-type semiconducting diamond from a mixture of graphite and catalyst metals ( $\mathrm{Ni}, \mathrm{Fe}$, etc.) and small amounts of $\mathrm{B}$, $\mathrm{Be}$, or $\mathrm{Al}$ at high pressures and high temperatures [28], [29]. It has been shown that a concentration of atomic $\mathrm{H}$ exceeding that of the equilibrium concentration associated with the thermal dissociation of the reactant hydrocarbon gases is necessary to achieve diamond growth [30], [31]. The technique used in [30], [31] consisted of a chemical vapor transport process in a closed tube coupled with the passage of $\mathrm{H}_{2}$ through an electric discharge to produce atomic $\mathrm{H}$. Following this work, various approaches have been reported including AC-plasma discharge [32], heated W filament chemical vapor deposition (CVD) [33]- [35], microwave plasma assisted CVD [36]-[40], RF-plasma assisted CVD [40], [41], electron-assisted CVD [42], [43], UV-assisted CVD [44], and the use of $\mathrm{H}$-ion beams [44]. Using high-pressure synthesis, Sumitomo Electric [47], [48] and DeBeers [46], [48] reported large type $\mathrm{Ib}$ diamond crystals of size $12 \mathrm{mmx} 12 \mathrm{~mm}$.

Monocrystalline diamond films necessary for microelectronic device applications have only been grown on diamond substrates. Attempts to deposit diamond thin films on less costly substrates have produced polycrystalline layers. The best of these films have grain sizes in the range of $1-10 \mathrm{~mm}$, which is approaching a useful size necessary to produce certain types of devices.

The production of device quality diamond requires techniques for introducing controlled amounts of dopant impurities. Because of the low diffusivity of most impurities in diamond, the diffusion doping technique does not work well. Diamond can be doped by ion implantation [49]-[58] or by CVD [59], [60]. Most attempts to dope diamond ntype use $\mathrm{Li}$ or $\mathrm{N}$, although $\mathrm{C}, \mathrm{P}, \mathrm{As}, \mathrm{O}$, and $\mathrm{Sb}$ have also 
Table 1 Material Parameters for Selected Semiconductors

\begin{tabular}{lccccc}
\hline Semiconductor & $\mathrm{Eg}(\mathrm{eV})$ & $\varepsilon_{r}$ & $\begin{array}{c}\kappa\left(\mathrm{W} /{ }^{\circ} \mathrm{K}-\mathrm{cm}\right) \\
\left(300^{\circ} \mathrm{K}\right.\end{array}$ & $\mathrm{E}_{\mathrm{c}}(\mathrm{V} / \mathrm{cm})$ & $\tau_{\text {minority }}(\mathrm{sec})$ \\
\hline $\mathrm{Si}$ & 1.12 & 11.9 & 1.5 & $3 \times 10^{5}$ & $2.5 \times 10^{-3}$ \\
$\mathrm{GaAs}$ & 1.42 & 12.5 & 0.54 & $4 \times 10^{5}$ & $\sim 10^{-8}$ \\
$\operatorname{InP}$ & 1.34 & 12.4 & 0.67 & $4.5 \times 10^{5}$ & $\sim 10^{-8}$ \\
Diamond & 5.5 & 5.5 & 30 & $(1.1-21.5) \times 10^{6}$ & $\sim 10^{-9}$ \\
$\alpha-\mathrm{SiC}$ & 2.86 & 10.0 & 4 & $(1-5) \times 10^{6}$ & $\sim(1-10) \times 10^{-9}$ \\
$3-\mathrm{SiC}$ & 2.2 & 9.7 & 4 & $(1-5) \times 10^{6}$ & $\sim(1-10) \times 10^{-9}$ \\
\hline
\end{tabular}

been reported. The electrical characteristics of synthetic n-type diamond are not currently adequate for use of this material in microwave and millimeter-wave electronic devices. Most current device effort is directed toward investigation of devices fabricated using p-type diamond. Natural semiconducting diamond is always p-type and synthetic $p$ type crystals can be obtained using boron doping. Boron doping by CVD [59], high pressure synthesis [29], and ion-implantation [51] yield activation energies of $0.013 \mathrm{eV}$, $0.2-0.35$, and $0.27-0.3 \mathrm{eV}$, respectively.

Many applications for diamond electronic devices have been proposed [61], [62]. Preliminary development of devices using both natural [63], [64] and synthetic crystals [65]-[68] have been reported. Thermistors made of natural [63] or synthetic [66] semiconducting diamonds can operate at temperatures from $2 \mathrm{~K}$ to $1000 \mathrm{~K}$. P-N junctions have been obtained by implanting lithium [56], [57] or arsenic [69] ions into p-type diamond crystals followed by high temperature annealing. An LED which emits in the wavelength range of $300-500 \mathrm{~nm}$ has been fabricated from an ion-implanted diamond [70]. The first diamond bipolar transistor was reported in 1982 [64]. The transistor exhibited very low current gain with an $\alpha \sim 0.1$. An improved $n-p-n$ bipolar transistor with a current gain of 0.8 was reported [69] by implanting As in natural semiconducting diamond. A point-contact transistor reported by Geis [67] exhibited a small signal current gain of 2-25 and a power gain of 6-35 at room temperature. At $510^{\circ} \mathrm{C}$ the current gain was $0.5-1.6$ and the power gain was 1.3-4.5. Initial development effort in the fabrication of diamond field-effect transistors has also been reported [71], [72]. Initial work has been on p-channel devices using boron doped diamond. A critical evaluation of the potential of diamond electronic devices has been presented by Collins [73].

\section{Material. AND Contact Properties}

The RF performance of electronic devices is determined by both the structural design of the particular device and the electronic transport characteristics of the material from which the device is fabricated. In addition, the manufacture of devices requires that low resistance ohmic contacts be fabricated between the semiconductor and external metal conductors. Rectifying contacts are also required for many devices in order to establish potential barriers for the control of currents within certain device structures. In general, contact technology is difficult on wide bandgap semiconductors, especially for ohmic contacts.

Electronic material parameters of interest are electron and hole transport characteristics as described by the charge carrier velocity-field and diffusion-field characteristics. The $\mathrm{v}$-E characteristic is generally described in terms of charge carrier mobility defined from the slope of the v-E characteristic at low, ohmic electric field and the saturated velocity defined when the carrier velocity obtains a constant, fieldindependent magnitude. The value of electric field at which saturation occurs is also of importance since it is an indicator of how fast the charge carriers can be accelerated to the saturation value. In general, the maximum frequency of a device will be obtained with the charge carriers at their saturated velocity. The critical electric field for dielectric breakdown and the thermal conductivity of the material determine the maximum power handling capability of the device. The breakdown field places a fundamental limit on the RF power that can be converted from the dc bias and the thermal conductivity determines the ease with which unconverted dc power can be extracted from the device. The unconverted dc power produces a temperature rise in the device which, in turn, degrades the electronic charge carrier transport characteristics. The dielectric constant and bandgap are also important material properties. The dielectric constant is a factor in determining the device impedance and the bandgap defines the upper temperature limit at which the device can be safely operated. The bandgap is also instrumental in determining the resistance of the device to radiation. Wide bandgap materials are radiation resistant and diamond, in particular, is the most radiation resistant semiconductor known. In general, low dielectric constant and high bandgap are desirable material characteristics. Minority carrier lifetimes are important when designing bipolar devices such as transistors and diodes where switching speed from a conductive to nonconductive state is of importance. A comparison of some of the most important material parameters for device applications for diamond and $\mathrm{SiC}$ and the most commonly used semiconductors is presented in Table 1. 


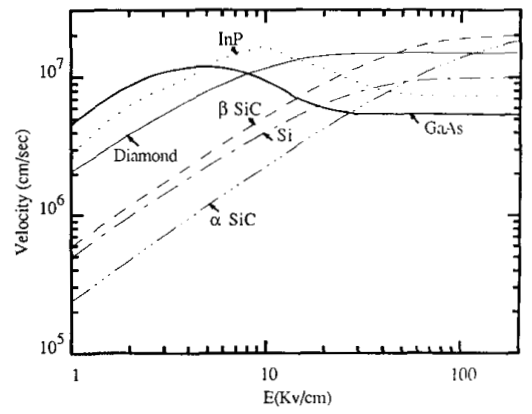

Fig. 1. Electron velocity versus electric field for several semiconductors at $N_{d}=10^{1} 7 \mathrm{~cm}^{-3}$.

Both experimental and theoretical velocity-field characteristics have been reported for diamond [74]-[77] and for $\mathrm{SiC}$ [74], [78], [79]. The velocity-field characteristics for both electrons and holes for several semiconductors are compared in Figs. 1 and 2. As indicated in Fig. 1, electron saturated velocity in both $\mathrm{SiC}$ and diamond is in the range of $(1-2) \times 10^{7} \mathrm{~cm} / \mathrm{s}$. The carrier velocities for diamond and $\mathrm{SiC}$ in Figs. 1 and 2 are approximate since there is some uncertainty in the exact value for both the mobility and saturated velocity due to few experiments being performed. All indications are that the saturated velocity is above $10^{7} \mathrm{~cm} / \mathrm{s}$ in both materials. The theoretical Monte Carlo results presented in [76] for diamond indicate room temperature electron and hole saturated velocities of $1.5 \times 10^{7} \mathrm{~cm} / \mathrm{s}$ and $1.2 \times 10^{7} \mathrm{~cm} / \mathrm{s}$, respectively. The electron low field mobility for an impurity concentration of $10^{17} \mathrm{~cm}^{-3}$ is about $1000 \mathrm{~cm}^{2} / \mathrm{V}$-s and $250 \mathrm{~cm}^{2} / \mathrm{V}$-s for diamond and $\alpha-\mathrm{SiC}$, respectively. The measured electron and hole mobilities in $\beta$-SiC have been reported to be as high as 600 and $650 \mathrm{~cm}^{2} / \mathrm{V}$-s, respectively, for doping concentrations of $2 \times 10^{16} \mathrm{~cm}^{-3}$ [80]. The theoretical results presented in [76] indicate electron and hole mobilities of $2200 \mathrm{~cm}^{2} / \mathrm{V}$-s and $1900 \mathrm{~cm}^{2} / \mathrm{V}$-s for undoped diamond. At an impurity concentration of $2 \times 10^{17} \mathrm{~cm}^{-3}$ the electron mobility is reduced to about $700 \mathrm{~cm}^{2} / \mathrm{V}$-s and at an impurity concentration of $10^{16} \mathrm{~cm}^{-3}$ the hole mobility is reduced to about $1300 \mathrm{~cm}^{2} / \mathrm{V}$-s. Hole mobilities in the range of $200-700 \mathrm{~cm}^{2} / \mathrm{V}$-s [51] and $850 \mathrm{~cm}^{2} / \mathrm{V}$-s [81] have been measured in boron doped diamond. The saturated velocity for holes in $\mathrm{SiC}$ is about $1 \times 10^{7} \mathrm{~cm} / \mathrm{s}$. The low field mobility for holes in $\alpha$-SiC, however, is very low (e.g., approximately $50 \mathrm{~cm}^{2} / \mathrm{V}$-s) and it is very difficult to observe saturation effects. This will severely limit the use of p-type $\alpha$-SiC in device applications.

The critical electric field for avalanche in diamond and $\mathrm{SiC}$ is significantly higher than for the commonly used semiconductors as shown in Fig. 3. The critical field significantly exceeds $10^{6} \mathrm{~V} / \mathrm{cm}$ in both diamond [82], [83] and $\mathrm{SiC}$ [84]-[87], compared to about $5 \times 10^{5} \mathrm{~V} / \mathrm{cm}$ for the other semiconductors. The ionization rates for diamond indicated in Fig. 3 were determined by applying the theory

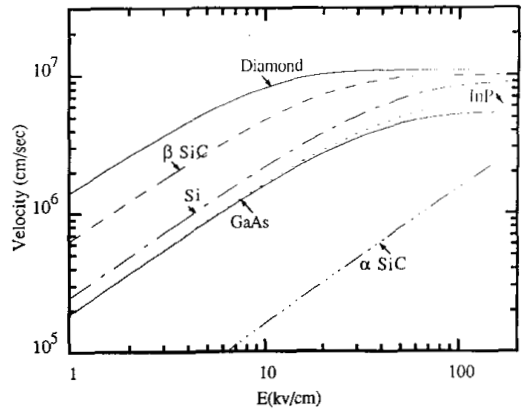

Fig. 2. Hole velocity versus electric field for several semiconductors at $N_{d}=10^{1} 7 \mathrm{~cm}^{-3}$.

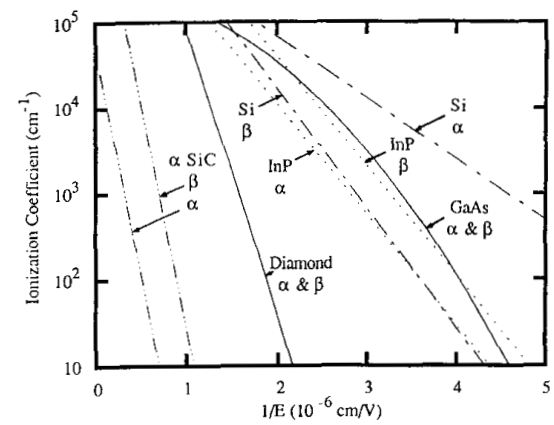

Fig. 3. Charge carrier ionization rates for several semiconductors.

of Baraff [88] to the experimental data reported in [82]. Baraff's theory describes the dependence of the ionization coefficients on the electric field by using three parameters: the Raman optical phonon energy, the ionization energy, and the carrier mean free path for optical phonon generation. Application of this theory yields ionization rates for electrons and holes in diamond that can be represented with the empirical expression

$$
\alpha=\beta=1.935 \times 10^{8} \exp \left(-7.749 \times 10^{6} / E\right)
$$

where $\alpha$ and $\beta$ are the ionization rates for electrons and holes, respectively, and are assumed equal. The ionization rates for $\mathrm{SiC}$ indicated in Fig. 3 were calculated using the data presented by Dmitriev et al. [86]. Dmitriev et al. find $6 \mathrm{H}-\mathrm{SiC}$ to be strongly anisotropic with respect to avalanche breakdown. They find the process of impact ionization to be influenced by superstructure splitting in the conduction band and that holes dominate the carrier generation. The avalanche generation by electrons is considered insignificant. Anikin et al. [87] also find the avalanche breakdown to be anisotropic and dominated by hole generation, but believe that the avalanche mechanism involves deep level states corresponding to residual impurities and not the conduction band superstructure. Epitaxial $6 \mathrm{H}-\mathrm{SiC}$ is typically grown in the $c$ direction and when the electric field is parallel to the $c$ axis the ionization rates are

$$
\beta=4.65 \times 10^{6} \exp \left(-1.2 \times 10^{7} / E\right)
$$




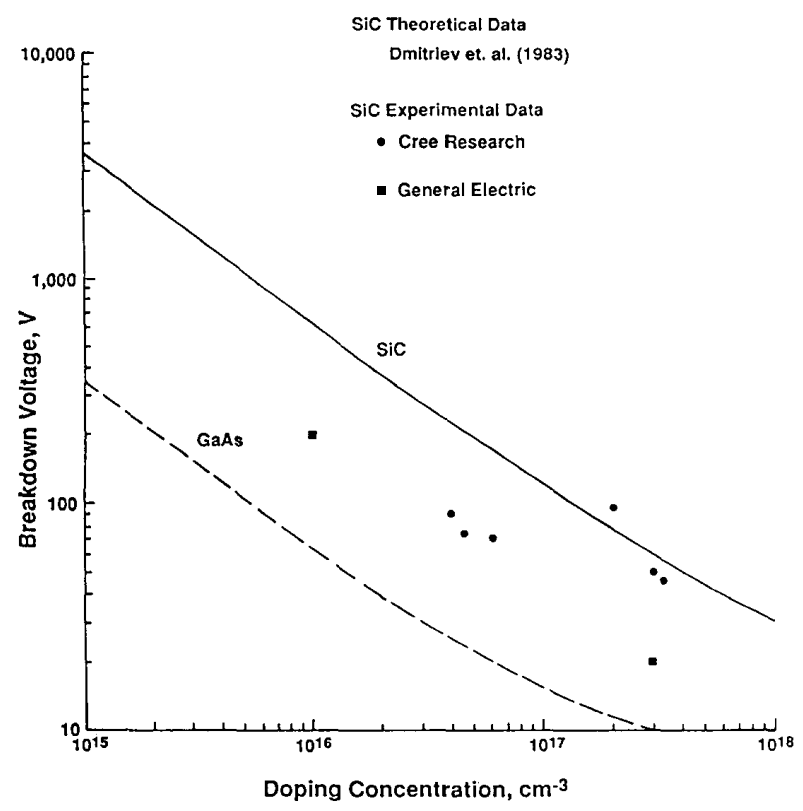

Fig. 4. Breakdown voltage versus doping for $\mathrm{SiC}$ and $\mathrm{GaAs}$.

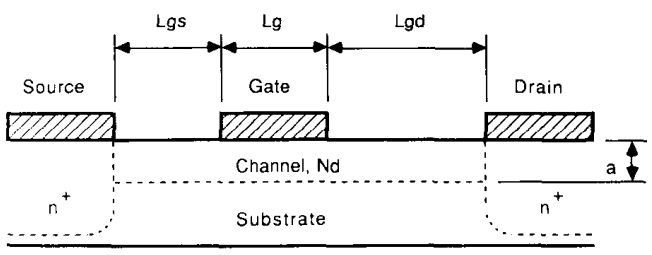

Fig. 5. Cross sectional sketch of a microwave MESFET.

and

$$
\alpha=\frac{\beta}{100} .
$$

A comparison of the breakdown voltage versus doping calculated using Dmitriev's results with experimental data is presented in Fig. 4, along with the breakdown voltage for GaAs. The data provided by Cree Research [89] is in agreement with the Dmitriev results. The General Electric data were taken from [84].

The high critical field indicates that devices fabricated from these materials will sustain large applied voltages before breakdown occurs. This factor is important when working with materials with relatively low mobilities since large electric fields are required to achieve carrier velocity saturation. Also, high breakdown voltage allows large bias to be applied with corresponding increase in RF output power. High power operation produces significant heat dissipation and thermal conductivities are important. Diamond and $\mathrm{SiC}$ both have high thermal conductivity as indicated in Table 1.

Both ohmic and rectifying contacts are required in device fabrication. Contact technology, however, is difficult on wide bandgap semiconductors. When metals are placed upon these materials rectifying behavior is generally obtained. Schottky contacts on diamond have been formed by vacuum evaporation of various metals [65], [67], [90], [91]. The height of the potential barrier is essentially independent of the metal due to surface pinning and has a value in the range of $1.3-1.7 \mathrm{eV}$. The room temperature reverse bias breakdown voltages for nickel-diamond [91] and tungstendiamond [67] contacts have been measured to be $250 \mathrm{~V}$ and $120-350 \mathrm{~V}$, respectively. A study of Schottky contacts produced from tungsten on boron-doped diamond has been reported [67]. As a result of the low ionization of the B acceptors (energy level at about $0.3 \mathrm{eV}$ above the valence band) at room temperature, the turn-on voltages of the 100 $\mu \mathrm{m}^{2}$ diodes exceeded $4 \mathrm{~V}$ and the series resistance ranged from 1 to $2 \mathrm{k} \Omega$. An ideality factor of 2 and a barrier height of 1-3 V were determined from I-V measurements taken at $580^{\circ} \mathrm{C}$ where most of the acceptors are ionized. Similar characteristics were measured at $700^{\circ} \mathrm{C}$. It has been shown that proper chemical cleaning of the borondoped diamond surface allows the fabrication of Au-gate Schottky diodes with excellent rectifying characteristics [92]. The best rectifying $p-n$ junctions in diamond have been produced by implantation of $\mathrm{Li}$ ions into p-type crystals followed by annealing at $1430^{\circ} \mathrm{C}$ [57], [93]. Good rectifying contacts to $\mathrm{SiC}$ have been formed by deposition of $\mathrm{Ti} / \mathrm{Au} \mathrm{[11]} \mathrm{and} \mathrm{thermal} \mathrm{evaporation} \mathrm{of} \mathrm{Au}$ [10]. Gold, 

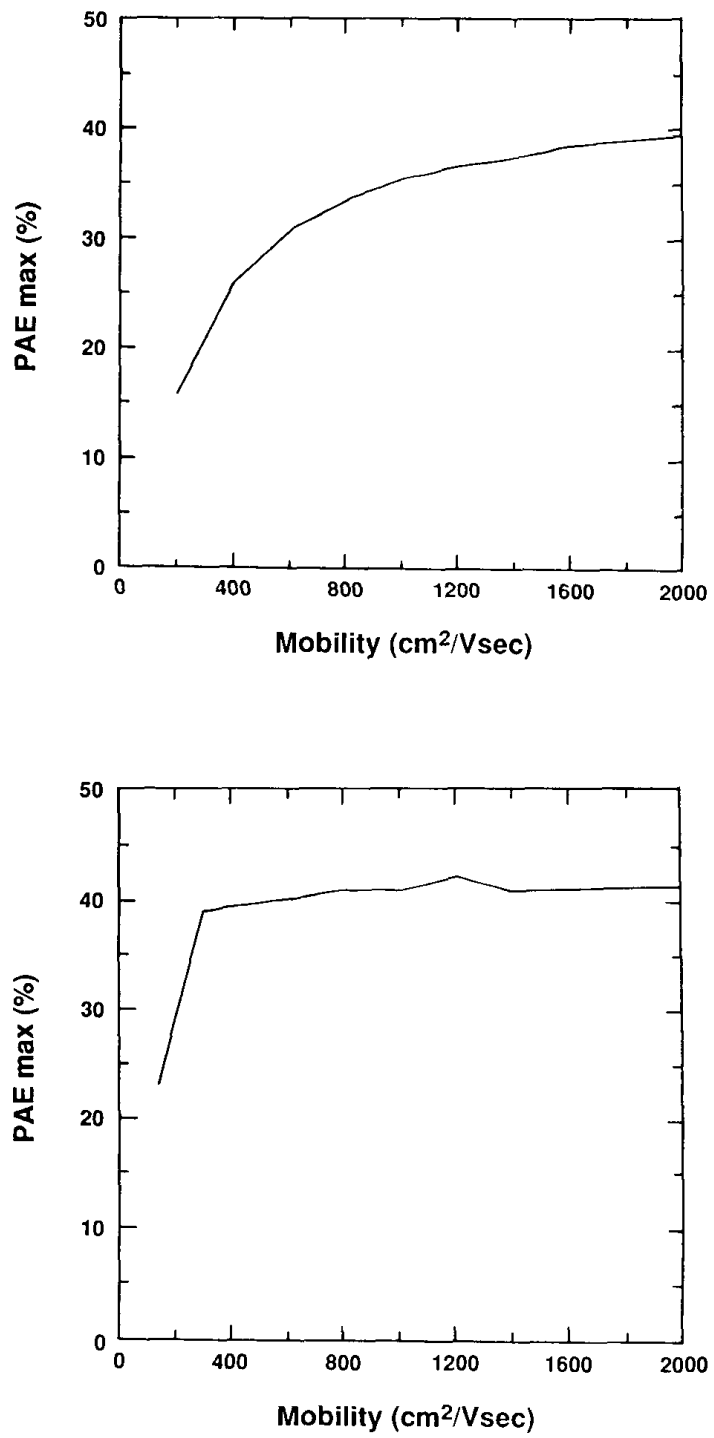

Fig. 6. RF performance versus charge carrier low-field mobility for MESFET's biased at $V_{d s}=20 \mathrm{~V}$ for a class A operation at $10 \mathrm{GHz}$ with (a) $1 \mu \mathrm{m}$ gate length, and (b) $0.5 \mu \mathrm{m}$ gate length.

which is the most successful Schottky material for SiC has several disadvantages including poor adherence to $\mathrm{SiC}$ and reaction with $\mathrm{SiC}$ above $400^{\circ} \mathrm{C}$. There is interest in refractory metals and refractory metal silicides (e.g., $\mathrm{PtSi}_{\mathrm{x}}$ ) for use as Schottky barriers on SiC. Rectifying p-n junctions in $\mathrm{SiC}$ are formed by in situ doping during growth or by ion-implantation. Typical p-type and n-type dopants are $\mathrm{B}$ or $\mathrm{Al}$ and $\mathrm{P}$ or $\mathrm{N}$, respectively. Diodes typically exhibit high reverse voltages with low leakage current, high current carrying capability and fast switching speed. High temperature operation is possible and no significant degradation in junction characteristics are observed, at least to $350^{\circ} \mathrm{C}$. Due to the large bandgap of $\mathrm{SiC}$ the build-in potential is relatively high and has a value in the range of
2.4-2.5 V, compared to $0.7-1.0 \mathrm{~V}$ obtained with GaAs and Si. Ideality factors for $\mathrm{SiC}$ junctions are generally about 1.6-2.0, indicating a significant generation-recombination current mechanism. The absence of a pure diffusion current (which would be indicated by an ideality factor approaching unity) is consistent with the low intrinsic density of $n_{j} \sim 10^{-5}$ $\mathrm{cm}^{-3}$ characteristic of $\mathrm{SiC}$. Due to the high critical field $\mathrm{SiC}$ diodes have high breakdown voltage (e.g., $\mathrm{V}_{\mathrm{B}}>400 \mathrm{~V}$ are easily achieved). Reverse leakage currents can be very low due to the wide bandgap and reverse saturation current densities in the range $\mathrm{J}_{\mathrm{s}} \sim 10^{-14} \mathrm{~A} / \mathrm{cm}^{2}$ have been obtained.

Ohmic contacts to diamond have demonstrated very high electrical resistance due to the large potential barrier of approximately $4 \mathrm{eV}$ at the diamond/metal interface [94]. Diamond is one of the least reactive of the elements and contact formation is hindered by poor adherence which contributes to high contact resistance. Most initial work with diamond devices used techniques such as tungsten point contact or silver paint to contact the semiconductor. The resulting contacts were characterized with high resistance (e.g., $\sim \mathrm{k} \Omega$ and larger). More recent work has obtained much improved ohmic contact performance using annealed $\mathrm{Ta} / \mathrm{Au}$ and $\mathrm{Ti} / \mathrm{Au}$ deposits on polished diamond surfaces [95], [96]. A thin film of a strong carbide forming metal is deposited on the semiconducting diamond surface and annealed to cause a chemical reaction between the diamond and metal. Metals such as tantalum, molybdenum, and titanium can be deposited and annealed to form reduced resistance contacts that adhere well to the diamond. It has also been reported that exposure of the diamond film surface to a hydrogen plasma results in the formation of a conductive layer which can be used to obtain linear I$\mathrm{V}$ characteristics [92]. The contact resistivity obtained on diamond, however, remains large and must be reduced if high performance electronic devices are to be fabricated. Ohmic contacts to $\mathrm{SiC}$ can be formed by deposition of metals such as Ni, Ag, Ta, W, Mo, and Ti. Sputtered $\mathrm{TaSi}_{2}$ has provided a good ohmic contact to n-type $\beta$-SiC; however, e-beam evaporation of elemental Ta has produced ohmic contacts on this material with contact resistivities of $\mathrm{Rc} \sim 10^{-5} \Omega-\mathrm{cm}^{2}$, which is an order of magnitude better than obtained using the $\mathrm{TaSi}_{2}$. Contacts to $\alpha$-SiC are not well established, although sintered $\mathrm{Ni}$ and a $94 \% \mathrm{Au} / 6 \%$ Ta alloy have been used. This material produces contact resistivities in the range of $\mathrm{Rc} \sim 10^{-3} \Omega-\mathrm{cm}^{2}$.

\section{Diamond And Sic Electronic Devices For HIGH FREQUENCY POWER APPLICATIONS}

In order to investigate the RF performance potential of diamond and $\mathrm{SiC}$ electronic devices, computer simulations were performed. The investigation utilizes physically based, theoretical computer models for the MESFET [97] and IMPATT diode [98]. The models have demonstrated excellent accuracy in predicting the RF performance of a variety of experimental devices fabricated from $\mathrm{Si}, \mathrm{GaAs}$, and InP. The models require material parameters, device designs, and operating conditions as input data and provide 
calculations of the dc and RF performance. The bipolar simulations were performed using a commercially available nonlinear device/circuit simulator [99]. The simulator requires that an equivalent circuit be established and, for this work, the equivalent circuit element values were determined from design calculations determined from the physical operation of the device. Device structures were designed to produce optimum RF output power and power-added efficiency at a variety of microwave and millimeter-wave frequencies. The results of the calculations indicate the RF potential of the wide bandgap materials for use in these applications. Only power applications were considered and no attempt was made to consider the noise performance of the devices. However, due to relatively low carrier mobility of the wide bandgap materials compared to $\mathrm{GaAs}$, the noise performance of diamond and $\mathrm{SiC}$ devices is expected to be inferior to $\mathrm{GaAs}$ devices.

\section{A. MESFET's}

The MESFET simulator [97] used in this work was originally developed for studies of GaAs devices. The device model is based upon efficient solutions of the basic semiconductor device equations and, therefore, contains a comprehensive description of the physical operation of the device. Major physical phenomena known to be of importance to device operation are included. The model accepts as input information material data such as charge carrier transport characteristics, breakdown parameters, thermal conductivity and dielectric constant, as well as device design information such as geometry, doping profile data and contact characteristics. Bias, RF circuit, and operating conditions must also be supplied.

For this work, the simulator was supplied with material parameters for $\mathrm{SiC}$ and diamond and MESFET structures were designed that resulted in optimized RF performance. The high frequency performance was determined for devices embedded in a realistic RF circuit. Therefore, impedance matching considerations were significant in determining device size limitations for maximum RF output power. Similar devices fabricated from $\mathrm{GaAs}$ were also investigated for comparison purposes.

A cross section of the MESFET device structure investigated is shown in Fig. 5. The MESFET has two ohmic contacts (the source and drain) separated by some distance, usually in the range of 3 to $10 \mu \mathrm{m}$. A rectifying Schottky contact (the gate) is located between the two ohmic contacts. Typically, the gate length is on the order of 0.1 to $2 \mu \mathrm{m}$ for modern microwave devices. The width of the device scales with frequency and typically ranges from about $50 \mu \mathrm{m}$ for millimeter wave devices, to $1-10 \mathrm{~mm}$ for power microwave devices. All three contacts are located on the surface of a thin conducting layer (the channel) which is located on top of a high resistivity, nonconductive substrate to form the device. In operation, the drain contact is biased at a specified potential (positive drain potential for an n-channel device) and the source is grounded. The flow of current through the conducting channel is controlled by negative dc and superimposed RF potentials applied to the

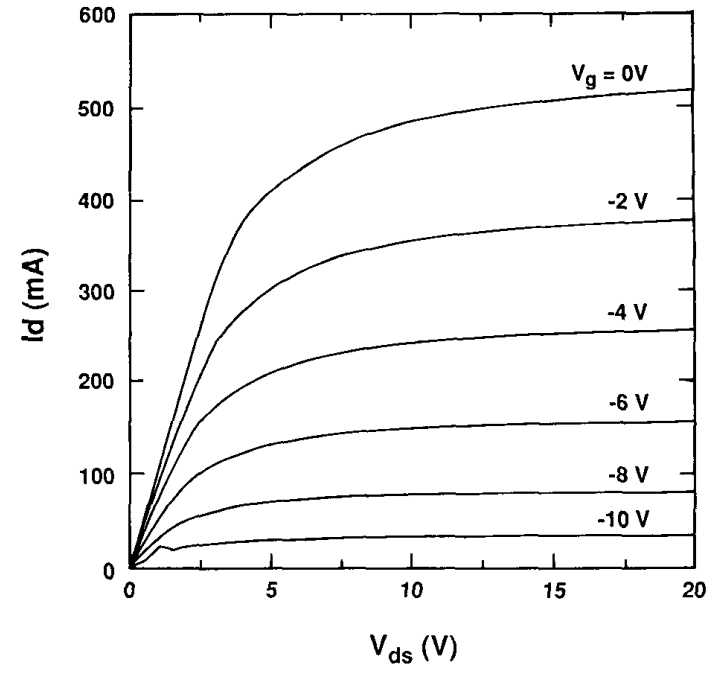

Fig. 7(a). I-V characteristics for a diamond MESFET $\left(L_{g}=0.5 \mu \mathrm{m}\right.$, $W=1 \mu \mathrm{m})$.

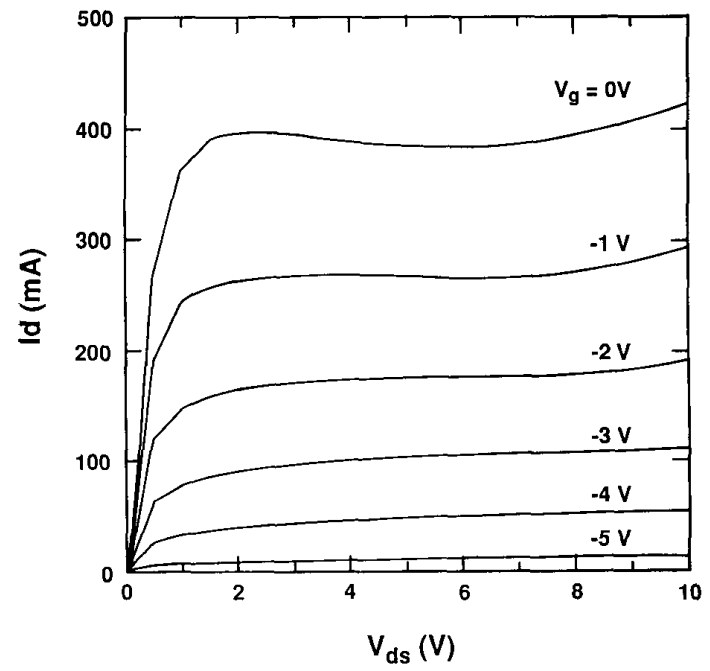

Fig. 7(b). 1-V characteristics for a GaAs MESFET $\left(L_{g}=0.5 \mu \mathrm{m}\right.$, $W=1 \mu \mathrm{m})$.

gate, which modulate the channel current and provides RF gain.

The parameters used for the diamond and SiC MESFET's and also for a similar GaAs device are indicated in Table 2. The diamond MESFET is assumed to have a Schottky gate contact fabricated using gold. The drain and source contacts are assumed ohmic with a specific contact resistivity of $\mathrm{Rc} \sim 10-4 \Omega-\mathrm{cm}^{2}$. A contact resistivity of this value is sufficient for microwave power applications where large contact size helps reduce total contact resistance. However, 
Table 2 MESFET Parameter Values Used in the Simulations

\begin{tabular}{llll}
\hline & & \multicolumn{2}{c}{ Value } \\
\cline { 3 - 4 } Parameter & \multicolumn{1}{c}{ Diamond } & $\alpha$-SiC & GaAs \\
\hline $\mathrm{L}_{\mathrm{g}}$ & $(0.5-1) \mu \mathrm{m}$ & $(0.5-1) \mu \mathrm{m}$ & $0.5 \mu \mathrm{m}$ \\
$\mathrm{L}_{\mathrm{ds}}$ & $3.5 \mu \mathrm{m}$ & $3.5 \mu \mathrm{m}$ & $3.5 \mu \mathrm{m}$ \\
$\mathrm{L}_{\mathrm{gs}}$ & $1 \mu \mathrm{m}$ & $1 \mu \mathrm{m}$ & $1 \mu \mathrm{m}$ \\
$\mathrm{N}_{\mathrm{d}}$ & $4 \times 10^{17} \mathrm{~cm}^{-3}$ & $2.4 \times 10^{17} \mathrm{~cm}^{-3}$ & $2.0 \times 10^{17} \mathrm{~cm}^{-3}$ \\
$\mathrm{a}$ & $0.15 \mu \mathrm{m}$ & $0.25 \mu \mathrm{m}$ & $0.23 \mu \mathrm{m}$ \\
$\mathrm{W}$ & $1 \mathrm{~mm}$ & $1 \mathrm{~mm}$ & $1 \mathrm{~mm}$ \\
$\Phi_{\mathrm{bi}}(\mathrm{Au})$ & $1.71 \mathrm{eV}$ & $1.95 \mathrm{eV}$ & $0.6 \mathrm{eV}$ \\
$\mathrm{R}_{\mathrm{C}}$ & $\sim 10^{-4} \Omega-\mathrm{cm}^{2}$ & $\sim 10^{-5} \Omega-\mathrm{cm}^{2}$ & $\sim 10^{-6} \Omega-\mathrm{cm}^{2}$ \\
\hline
\end{tabular}

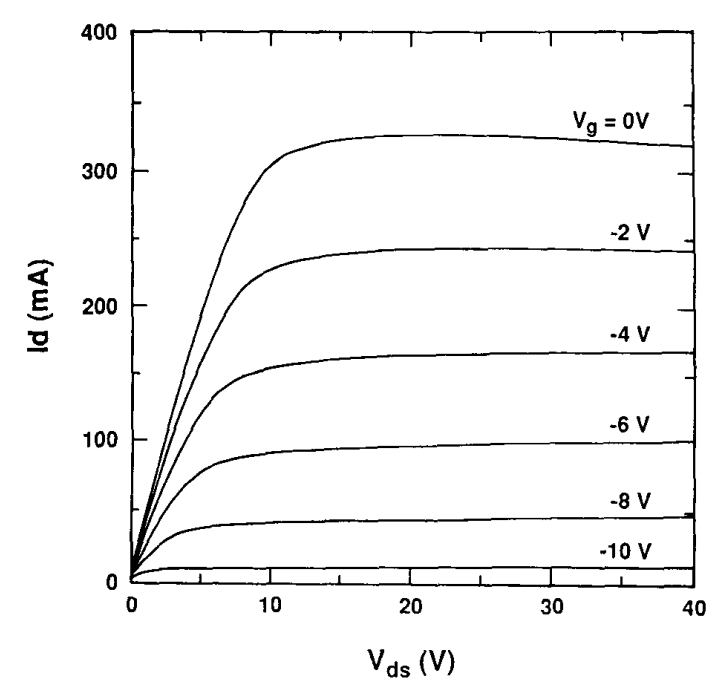

Fig. 8(a). I-V characteristics for a SiC MESFET ( $L_{q}=1 \mu \mathrm{m}, W=1$ $\mathrm{mm})$.

for millimeter-wave devices the contact resistivity will need to be reduced to approximately $\mathrm{Rc} \sim 10^{-6}-10^{-7} \mathrm{~W}-\mathrm{cm}^{2}$ in order to produce low resistance contacts. Contact size scales with frequency and reduced contact area is required for mm-wave operation.

Mobility directly affects channel current and, therefore, RF performance. The effect of varying mobility upon the maximum power-added efficiency of power MESFET's is illustrated in Fig. 6(a) and 6(b), respectively for devices with $1 \mu \mathrm{m}$ and $0.5 \mu \mathrm{m}$ gate lengths biased with a drain voltage of $20 \mathrm{~V}$ for class $A$ operation at $10 \mathrm{GHz}$. The calculations shown in Fig. 6 apply to both $\mathrm{SiC}$ and diamond MESFET's. As indicated, mobility has a significant effect upon the RF performance of the device, especially when the mobility is low. The power-added efficiency increases with mobility until a critical value of about $1500 \mathrm{~cm}^{2} / \mathrm{V}$ -

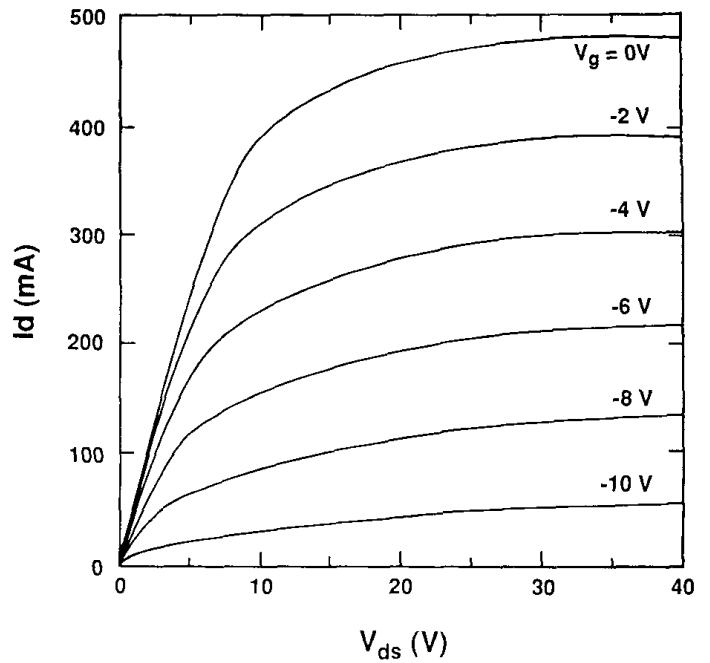

Fig. 8(b). I.V characteristics for a SiC MESFET $\left(L_{g}=0.5 \mu \mathrm{m}, W=1\right.$ $\mathrm{mm}$ ).

$\mathrm{s}$ is reached for the $1-\mu \mathrm{m}$ gate length device. Mobilities above this value do not result in significantly improved RF power performance. The limiting effect of mobility is related to the magnitude of the electric field in the channel under the gate electrode. This region consists of essentially two regions: a low electric field region where carrier transport is dominated by the mobility (ohmic region) and a high field region where saturated carrier velocity occurs. The boundary between these two regions depends upon the device structure, primarily gate length and bias conditions, as well as the magnitude of the mobility. Power devices are typically operated at high drain bias. A high electron mobility results in a minimized ohmic region under the gate electrode since the carriers are rapidly accelerated by the high channel field. This allows the channel current to be determined by the saturated velocity 


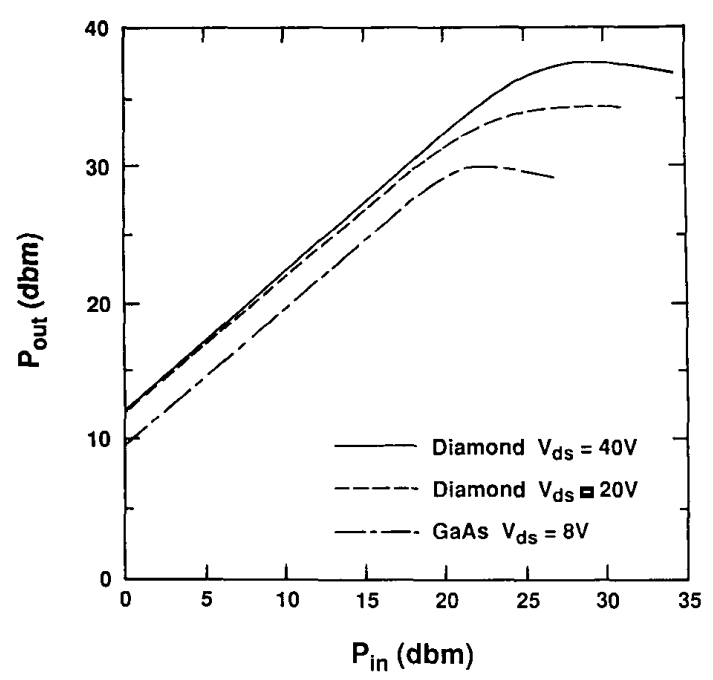

Fig. 9(a). RF output power versus input power for diamond and $\mathrm{GaAs}$ MESFET's ( $F=10 \mathrm{GHz}, L_{g}=0.5 \mu \mathrm{m}, W=1 \mathrm{~mm}$, Class A).

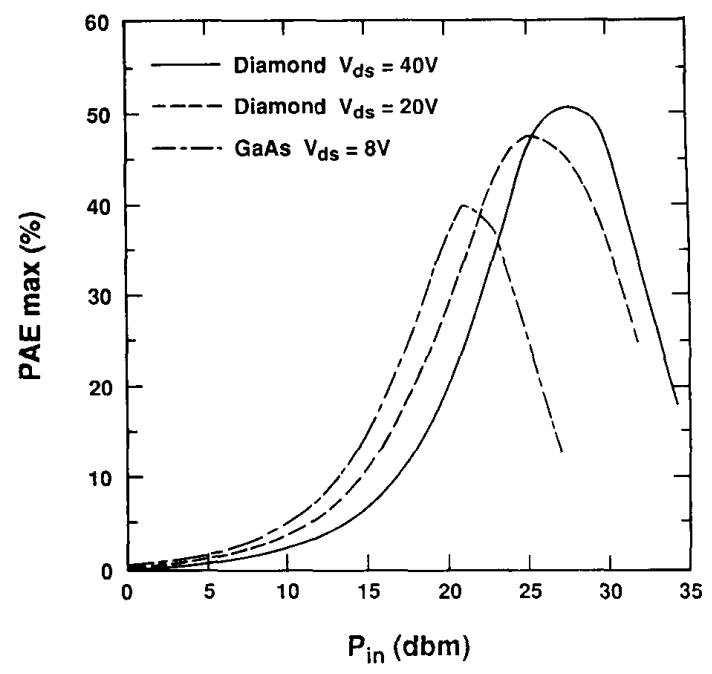

Fig. 9(b). Power-added efficiency versus input power for diamond and GaAs MESFET's $\left(F=10 \mathrm{GHz}, L_{g}=0.5 \mu \mathrm{m}, W=1 \mathrm{~mm}\right.$, Class A).

and thereby maximized. For mobilities above about 1500 $\mathrm{cm}^{2} / \mathrm{V}$-s essentially the entire channel under the gate is at or above the saturation field. Therefore no improvement is observed for increased values of mobility.

For mobilities below about $1000 \mathrm{~cm}^{2} / \mathrm{V}$-s RF performance degradation in the $1-\mu \mathrm{m}$ gate length device occurs. The degradation results from an increased ohmic region in the channel which limits the channel current. The degradation increases with reductions in mobility and, for mobility

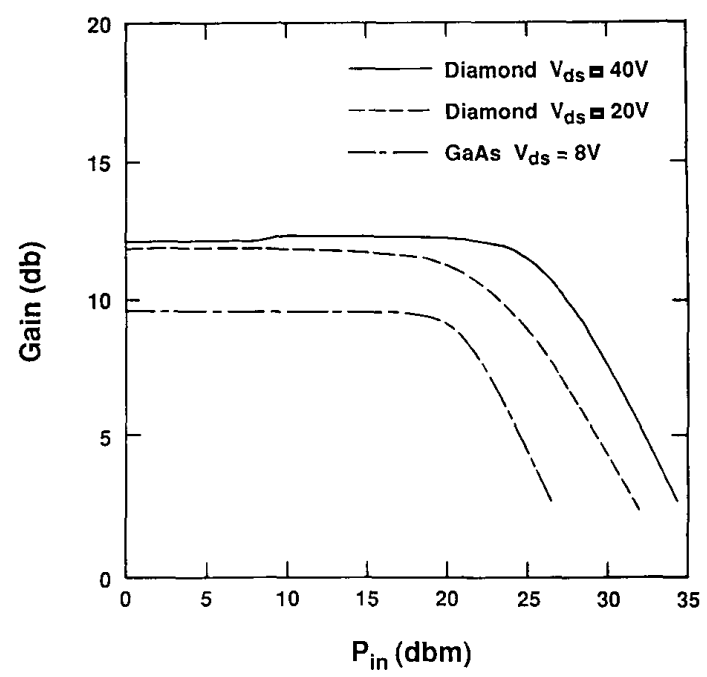

Fig. 9(c). Gain versus input power for diamond and GaAs MESFET's ( $F=10 \mathrm{GHz}, L_{g}=0.5 \mu \mathrm{m}, W=1 \mathrm{~mm}$, Class A).

in the range of about $250 \mathrm{~cm}^{2} / \mathrm{V}$-s, significant degradation in RF performance is observed as indicated in Fig. 6(a). At this value of mobility a large portion of the conducting channel is in the ohmic region, thereby minimizing the effects of velocity saturation and reducing channel current.

The severe degradation shown for the $1-\mu \mathrm{m}$ gate length device for a mobility of $250 \mathrm{~cm}^{2} / \mathrm{V}$-s could be reduced by techniques designed to increase the magnitude of the electric field in the channel. For example, a reduction in gate length is known to increase channel electric field and produce increased channel current. This is the technique generally employed in the fabrication of GaAs devices [100]. The effect of reducing gate length to $0.5 \mu \mathrm{m}$ is shown in Fig. 6(b). The greater channel electric field reduces the critical mobility required to achieve saturation to a value of about $300 \mathrm{~cm}^{2} / \mathrm{V}$-s.

Increased electric field also results from increased drain bias. For class A operation the drain bias can be increased until it is about $40-50 \%$ of the gate-drain breakdown voltage. For modern $\mathrm{Si}$ and $\mathrm{GaAs}$ microwave devices the relatively low breakdown field limits breakdown voltages to about $20-25 \mathrm{~V}$ and drain bias voltages to the range of 8-12 $\mathrm{V}$. The high breakdown fields of diamond and $\mathrm{SiC}$ should permit these devices to be biased at much higher voltages. This will, in fact, be necessary if efficient RF performance is to be obtained.

Low charge carrier mobility also degrades device performance through increased parasitic resistances. Both the drain (Rd) and source (Rs) resistances are increased in direct proportion to mobility. This effect is very significant for very high frequency (mm-wave) and/or low noise devices, or digital logic MESFET's, which are fabricated with relatively short gate widths. Power MESFET's, however, have large gate widths which, due to aspect ratio 


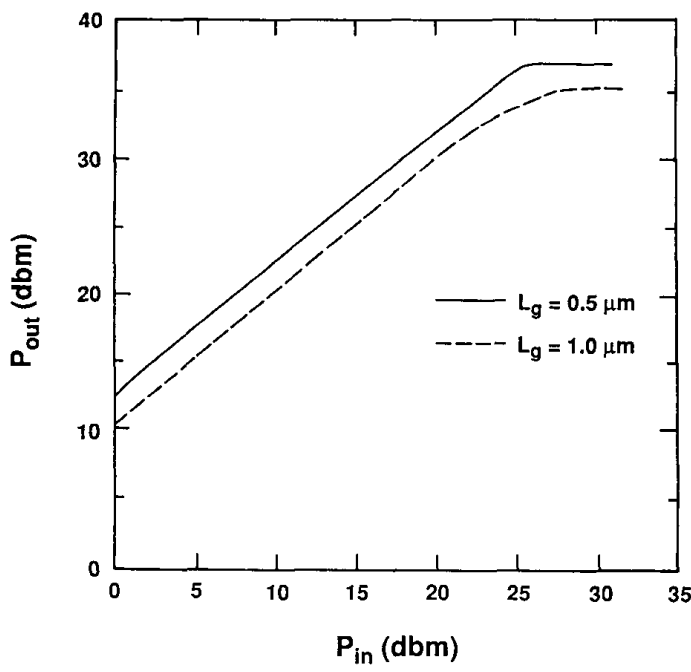

Fig. 10(a). RF output power versus input power for $0.5 \mu \mathrm{m}$ and $1 \mu \mathrm{m}$ gate length SiC MESFET's ( $F=10 \mathrm{GHz}, W=1 \mathrm{~mm}$, Class A).

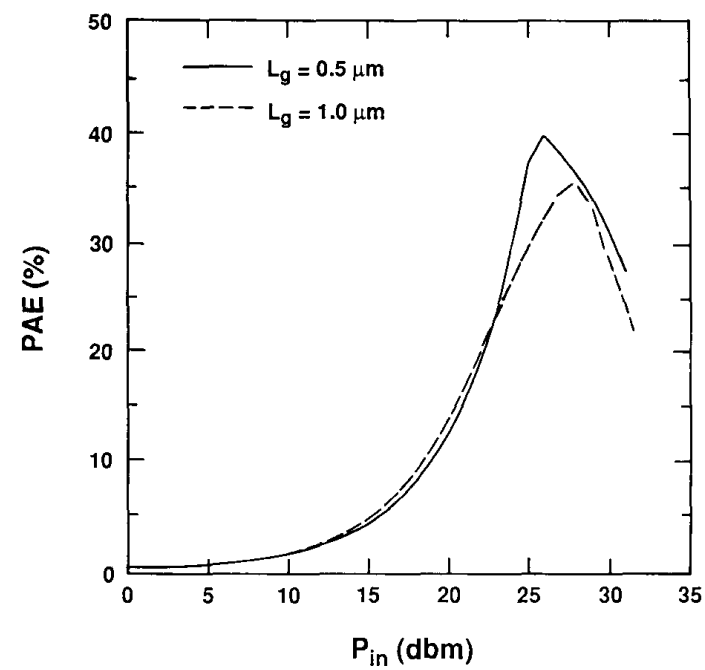

Fig. 10(b). Power-added efficiency versus input power for $0.5 \mu \mathrm{m}$ and $1 \mu \mathrm{m}$ gate length SiC MESFET's ( $F=10 \mathrm{GHz}, W=1 \mathrm{~mm}$, Class A)

considerations, minimize the significance of low charge carrier mobility. The parasitic resistances are typically sufficiently low due to the wide gate width that even order of magnitude decreases in mobility do not seriously degrade device performance.

In order to determine the RF capability of diamond and $\mathrm{SiC}$ MESFET's the device structures were optimized to produce a maximum power-added efficiency at an input drive level sufficient to produce a one $\mathrm{dB}$ compression in the gain. The devices were biased for class $\mathrm{A}$ operation at

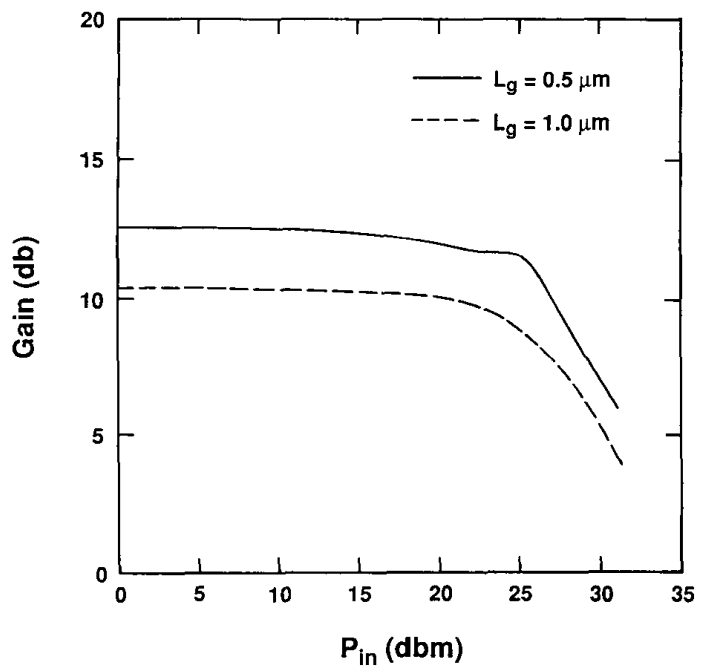

Fig. 10(c). Gain versus input power for $0.5 \mu \mathrm{m}$ and $1 \mu \mathrm{m}$ gate length SiC MESFET's ( $F=10 \mathrm{GHz}, W=1 \mathrm{~mm}$, Class A).

a drain current of $I_{d s}=I_{d s s} / 2$, where $I_{d s s}$ is the channel current with zero bias applied to the gate electrode. The calculations were performed for an operating frequency of $10 \mathrm{GHz}$ with the device embedded in an RF circuit and the circuit was tuned to obtain the desired performance.

A comparison of the $\mathrm{dc} I-\mathrm{V}$ characteristics obtained for the diamond and GaAs devices are shown in Fig. 7(a) and $7(\mathrm{~b})$, respectively. The maximum transconductances are $g_{m}=76 \mathrm{mS} / \mathrm{mm}$ and $g_{m}=190 \mathrm{mS} / \mathrm{mm}$ for the diamond and GaAs devices, respectively. The lower transconductance of the diamond MESFET is due to a larger pinch-off voltage. The diamond device, however, produces a larger current than the GaAs device for similar bias voltages. This results from the greater saturation velocity of the charge carriers in diamond. In order to achieve current saturation, the diamond device requires larger drain voltages than the GaAs device. This is due to the lower mobility (by about a factor of six) of the charge carriers in diamond as compared to GaAs. The magnitude of the channel current is an indicator of the power capability of the device and the greater current of the diamond device is expected to translate into improved RF power performance. The dc I-V characteristics for the $\mathrm{SiC}$ device are shown in Fig. 8. One device is fabricated with a gate length of $1 \mu \mathrm{m}$, and the other device has a gate length of $0.5 \mu \mathrm{m}$. The maximum transconductances for the two devices are $g_{m}=37 \mathrm{mS} / \mathrm{mm}$ and $g_{m}=46 \mathrm{mS} / \mathrm{mm}$. The lower mobility of the charge carriers in SiC limit the channel current to values less than can be obtained with diamond for comparable gate length. Drain bias voltages in the range of $5-10 \mathrm{~V}$ are required to achieve current saturation.

A comparison of the RF power capability of the diamond and GaAs devices is shown in Fig. 9. The RF power, power- 


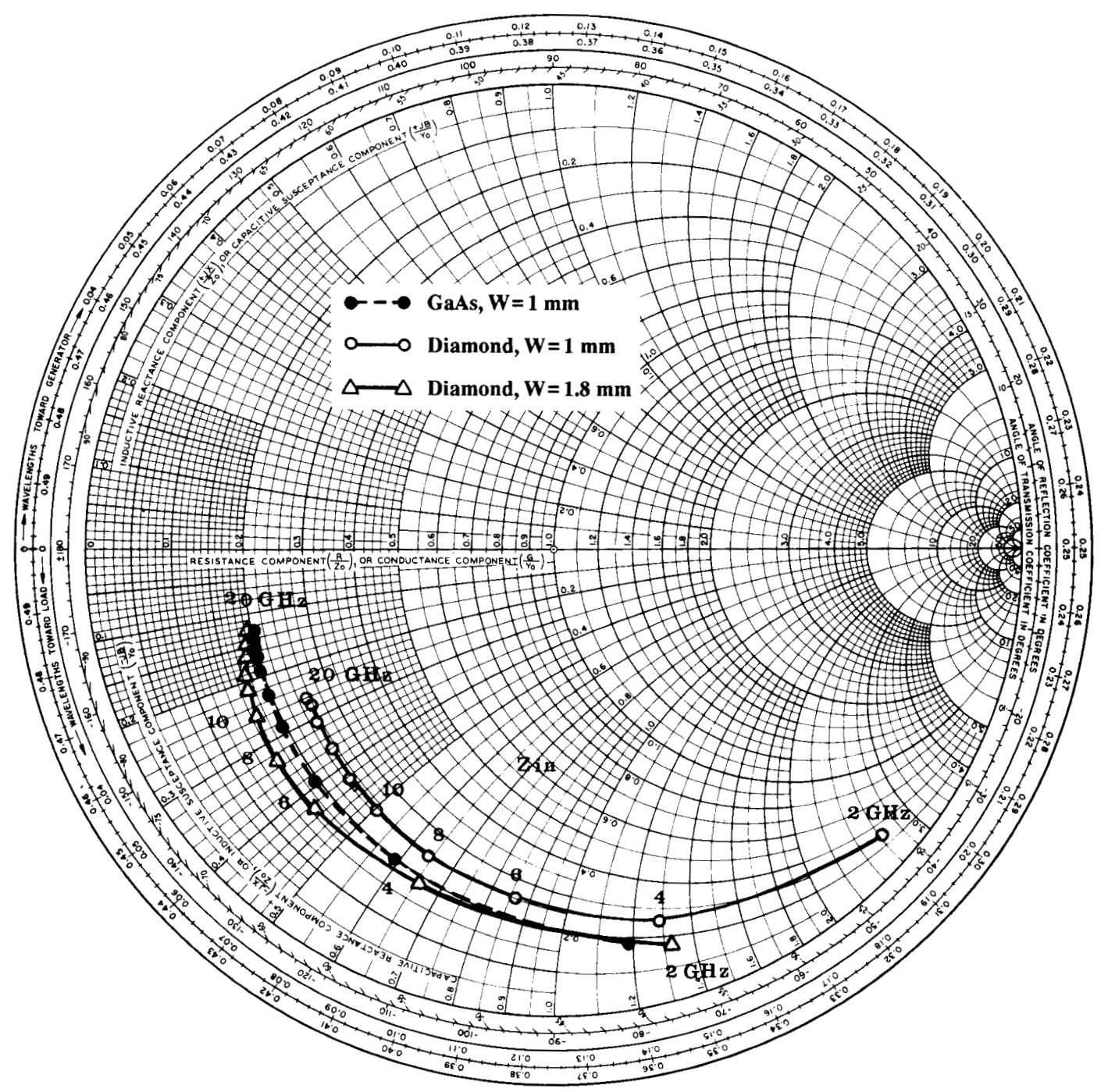

Fig. 11. Small-signal input impedances for diamond and GaAs MESFET's.

added efficiency, and gain are shown in Figs. 9(a), 9(b), and $9(\mathrm{c})$, respectively. The diamond MESFET performance is determined for drain bias voltages of $V_{d s}=20$ and $40 \mathrm{~V}$. The GaAs device is operated at a drain bias of $V_{d s}=8 \mathrm{~V}$. The gate-drain breakdown voltage is critical in determining the magnitude of drain bias that can be applied. For GaAs devices with $1-\mu \mathrm{m}$ gate lengths, the gate-drain breakdown voltage is typically in the range of 15-20 V. Generally, a MESFET can only support a drain bias of about $40-50 \%$ of the breakdown voltage. Since the breakdown field in diamond is at least twice and as much as five times that in $\mathrm{GaAs}$, gate-drain breakdown voltages in the range of $40-100 \mathrm{~V}$ should be possible. For this reason, the diamond device was biased at the higher drain potentials. The higher drain voltages result in improved
RF performance as indicated in Fig. 9(a). The diamond device produces about $6 \mathrm{~W} / \mathrm{mm}$ of gate periphery RF power compared to about $1 \mathrm{~W} / \mathrm{mm}$ of $\mathrm{RF}$ power for the $\mathrm{GaAs}$ device. The power-added efficiencies for the two devices are comparable and in the range of $40-50 \%$. The diamond MESFET is more efficient (about ten percentage points) than the GaAs device. The linear gain of the diamond device is about $2-3 \mathrm{~dB}$ greater than that for the GaAs device. Also, the dynamic range (i.e., the range of input power for which the gain is constant) for the diamond device is about $5 \mathrm{~dB}$ greater than that for the GaAs device. The greater linear operating range of the diamond device produces lower magnitudes of the harmonic frequencies when the device is driven into saturation. This indicates that diamond devices may be useful in applications that 
Table 3 GaAs and Diamond MESFET Operation at $10 \mathrm{GHz}$ Device Input Impedance Matched to $1 \Omega$

\begin{tabular}{lcc}
\hline & GaAs & Diamond \\
\hline $\begin{array}{l}\text { Input Impedance }(\Omega) \\
\mathrm{Z}_{\text {in }} \text { for } \mathrm{W}=1 \mathrm{~mm}\end{array}$ & $10-\mathrm{j} 11.5$ & $12.5-\mathrm{j} 25$ \\
$\mathrm{Z}_{\text {in }}$ for max. width & $1-\mathrm{j} 1.15(10 \mathrm{~mm})$ & $0.7-\mathrm{j} 1.39(18 \mathrm{~mm})$ \\
$\mathrm{RF}$ Power at Max. Width $(\mathrm{W})$ & 8 & 225 \\
Thermal Resistance $\left({ }^{\circ} \mathrm{C} / \mathrm{W}\right)$ & 10.2 & 1.8 \\
$P_{\text {diss }}(\mathrm{W})$ & 15.8 & 187 \\
Power-Added Efficiency $(\%)$ & 30 & 36 \\
Channel Temp. Increase $\left({ }^{\circ} \mathrm{C}\right)$ & 113 & 215 \\
\hline
\end{tabular}

require linear performance, such as receiver input stages.

Similar calculations performed for SiC MESFET's with $1-\mu \mathrm{m}$ and $0.5-\mu \mathrm{m}$ gate lengths are shown in Fig. 10. The RF output power, power-added efficiency, and gain for class $\mathrm{A}$ operation at $10 \mathrm{GHz}$ are shown in Figs. 10(a), 10(b), and 10(c), respectively. The devices were biased with $V_{d s}=40$ $\mathrm{V}$. The $\mathrm{SiC}$ device produces about $5 \mathrm{~W} / \mathrm{mm}$ of $\mathrm{RF}$ power which also indicates improved RF performance of the SiC MESFET compared to the GaAs device. The lower RF power of the SiC MESFET compared to the diamond device is due to the reduced value of low field mobility and the corresponding reduction in the conducting channel current. The SiC MESFET is also capable of good power-added efficiency (greater than 30\%) and good gain. In particular, significant improvement in the RF performance of the device is observed for reduced gate length designs. High performance MESFET's fabricated from $\mathrm{SiC}$ will require submicron lithography. The gate-drain breakdown voltage of the SiC device should be comparable to or greater than that for the diamond device. The thermal conductivity of $\mathrm{SiC}$, however, is only about an eighth of that for diamond and this will limit the power performance of SiC devices to power levels less than can be achieved with diamond.

The calculations presented assumed a gate width of 1 $\mathrm{mm}$. While typical of device designs intended for $X$-band (i.e., 8-12 GHz) microwave applications, this does not represent the maximum device width that can be effectively utilized. The maximum gate width possible scales inversely with frequency and is determined by impedance matching, as well as dc power dissipation considerations. Increasing the gate width increases the RF current and, therefore, the RF power that is generated. However, as the device width is increased the input impedance of the device is reduced. About the lowest impedance that can be matched to a $50-\Omega$ circuit is $1 \Omega$. This criterion can be used to obtain an estimate of the maximum RF power capability of the device by increasing gate width until the input impedance is reduced to $1 \Omega$. The resulting device design can then be analyzed to determine the RF capability limits of the device. The results of this type of analysis are presented in Table 3 for both diamond and GaAs MESFET's. The phase velocity in diamond is significantly lower than that in GaAs due to the lower dielectric constant. An increased device impedance results. For example, the input impedances for diamond and GaAs MESFET's with 1-mm gate width are indicated on the Smith Chart shown in Fig. 11. The impedance loci are for a frequency band from $2-20 \mathrm{GHz}$. To reduce the diamond MESFET input impedance to a level equivalent to that for the GaAs MESFET allows the diamond gate width to be increased to $1.8 \mathrm{~mm}$. The increased gate width translates directly into increased channel current and RF power. As indicated in Table 3, for operation at $10 \mathrm{GHz}$, the maximum gate width in GaAs is $8 \mathrm{~mm}$ and $18 \mathrm{~mm}$ in diamond. Both devices produce power-added efficiencies greater than $30 \%$. Too large a gate width will, of course, produce channel heating, which will limit the RF performance of the device. The thermal resistances for the devices were calculated and used to determine the channel heating. At the power levels indicated in Table 3 , the temperature rise in the GaAs device is $113^{\circ} \mathrm{C}$ and $215^{\circ} \mathrm{C}$ in the diamond device. Both materials are able to support these temperatures. The maximum allowed channel temperature before damage occurs is approximately $200^{\circ} \mathrm{C}$ for GaAs and possibly in the range of $700^{\circ} \mathrm{C}-1000^{\circ} \mathrm{C}$ for diamond.

The operation of the SiC MESFET as a function of gate width was also investigated. In this study, however, the operation of the device embedded in an RF circuit was simulated and the gate width was increased until a degradation in PAE of between $20-25 \%$ was observed. This limit is arbitrary, but allows RF operation with good RF output power and PAE. Large gate widths can result in RF performance degradation due to distributed transmission line effects. To minimize these effects multiple gate fingers are used. A rule of thumb to avoid distributed effects is to design the maximum gate finger length to be no more than $1 / 20$ of a wavelength. Gate finger length, therefore, depends upon the operation frequency and for the $10 \mathrm{GHz}$ $\mathrm{SiC}$ MESFET is $250 \mu \mathrm{m}$.

The calculated dc I-V characteristics for the $10 \mathrm{GHz}$ device are shown in Fig. 12. With a gate width of $16 \mathrm{~mm}$, the device has an $I_{d s s}$ of about $7.7 \mathrm{~A}$ and a pinch-off voltage 


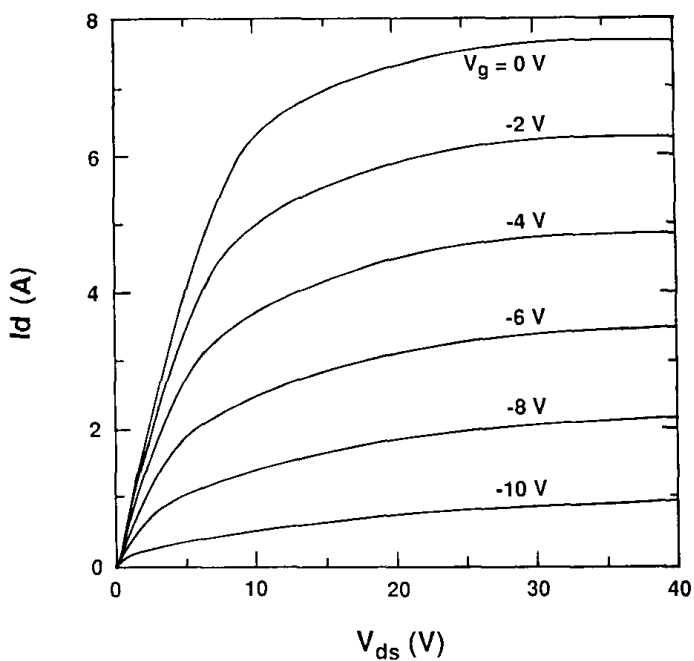

Fig. 12. I-V characteristics for a SiC MESFET with $L_{g}=0.5 \mu \mathrm{m}$ and $W=16 \mathrm{~mm}$.

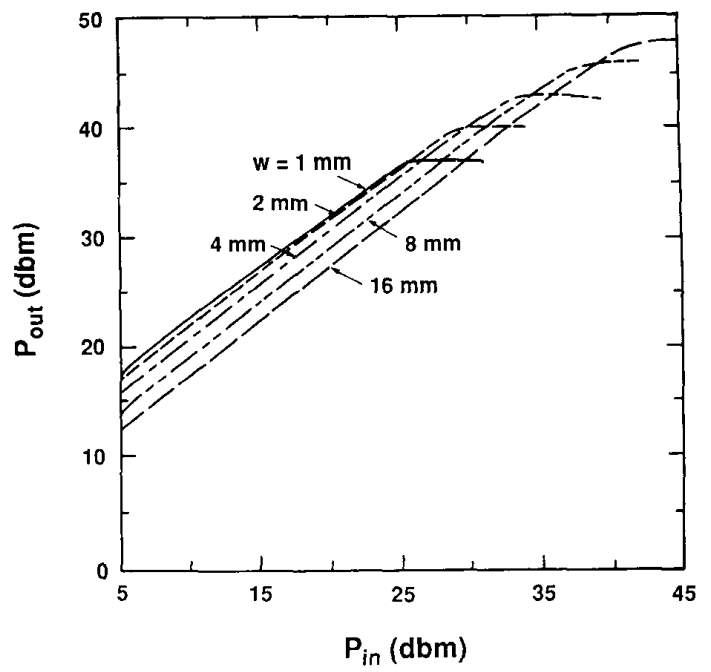

Fig. 13(a). RF output power versus input power for SiC MESFET's with $L_{g}=0.5 \mu \mathrm{m}$ and gate widths from $1-16 \mathrm{~mm}\left(F=10 \mathrm{GHz}, V_{d s}=40\right.$ $\mathrm{V}$, Class A).

of $V_{p}=-11.6 \mathrm{~V}$. The large gate width results in a reduced maximum transconductance of $30 \mathrm{mS} / \mathrm{mm}$, but good $\mathrm{RF}$ output power is obtained. For RF operation the device was biased at a drain voltage of $40 \mathrm{~V}$ and a channel current of $3.4 \mathrm{~A}$. The RF output power, PAE, and gain are shown in Figs. 13(a), 13(b), and 13(c), respectively. The device produces a maximum RF output power of $65 \mathrm{~W}$, a PAE of $23.4 \%$, and a linear gain of $7.3 \mathrm{~dB}$. The normalized RF output power is about $4 \mathrm{~W} / \mathrm{mm}$.

If efficient operation is to be obtained the excess dc power must be extracted from the device. The ability

TREW et al: : POTENTIAL OF DEVICES FOR POWER APPLICATIONS

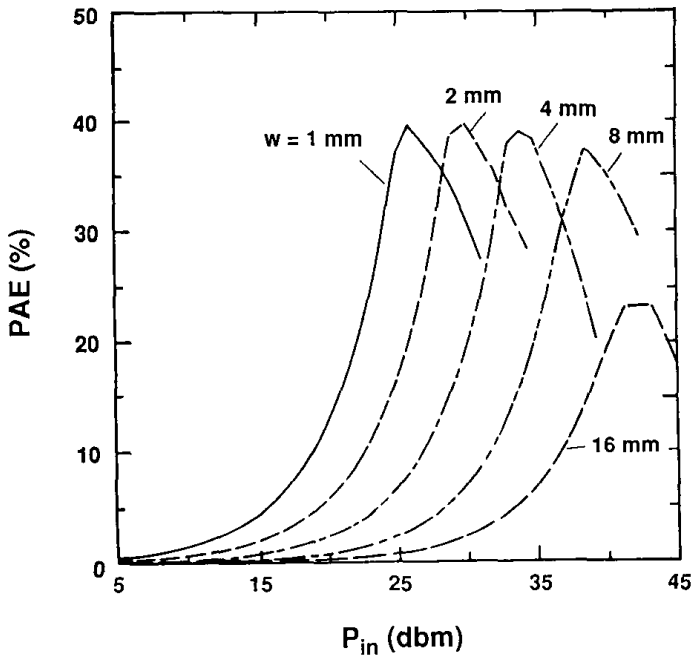

Fig. 13(b). Power-added efficiency versus input power for SiC MES FET's with $L_{g}=0.5 \mu \mathrm{m}$ and gate widths from $1-16 \mathrm{~mm}(F=10 \mathrm{GHz}$, $V_{d s}=40 \mathrm{~V}$, Class A).

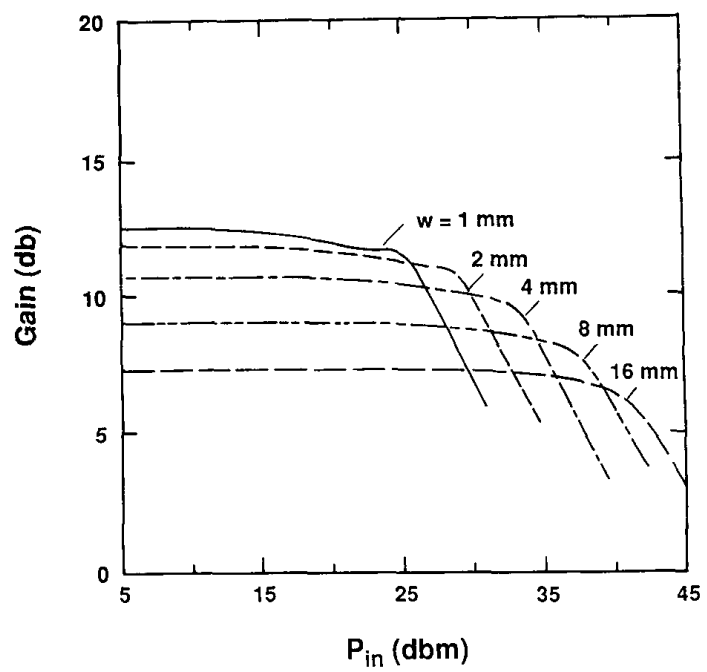

Fig. 13(c). Gain versus input power for SiC MESFET's with $L_{g}=0.5$ $\mu \mathrm{m}$ and gate widths from $1-16 \mathrm{~mm}\left(F=10 \mathrm{GHz}, V_{d s}=40 \mathrm{~V}\right.$, Class A).

of the device to dissipate excess energy is indicated by the thermal impedance or resistance of the device. The thermal resistance is a measure of the ease with which heat can flow from the conducting channel to the heat sink and it can be calculated from heat flow arguments or measured using a combination of pulse and dc operating conditions. Since at $300 \mathrm{~K}$ the thermal conductivity of SiC is about $4 \mathrm{~W} / \mathrm{K}-\mathrm{cm}$ compared to 1.5 and $0.54 \mathrm{~W} / \mathrm{K}-\mathrm{cm}$ for $\mathrm{Si}$ and $\mathrm{GaAs}$, respectively, significantly reduced thermal resistance should result. For example, a 1-mm gate width 
GaAs power MESFET typically has a thermal resistance of about $50^{\circ} \mathrm{C}-60^{\circ} \mathrm{C} / \mathrm{W}$. The largest contribution to the thermal resistance results from heat flow through the semiinsulating substrate. The resistance to heat flow from the conducting channel into the substrate is generally small, and the resistance to heat flow from the substrate into the heat sink can be minimized by using a good thermal conductor for the heat sink. Typically gold plated copper is used, but if improved thermal resistance is desired type II diamond heat sinks can be employed. Ceramics with good thermal characteristics such as metallized $\mathrm{BeO}$ are also used.

In order to minimize the thermal resistance of $\mathrm{GaAs}$ power MESFET's the semi-insulating substrate material is generally thinned to a thickness in the range of $50 \mu \mathrm{m}$. This results in a thermal resistance of about $60^{\circ} \mathrm{C} / \mathrm{W}$ for a $1-\mathrm{mm}$ gate width device. Based upon its significantly larger thermal conductivity a comparable SiC MESFET is calculated to have a thermal resistance of about $7^{\circ} \mathrm{C}-8^{\circ} \mathrm{C} / \mathrm{W}$. For a 40 $\mathrm{V}$ drain bias and a drain to source current of $I_{d s}=I_{d s s} / 2$ a channel temperature rise of approximately $60^{\circ} \mathrm{C}-80^{\circ} \mathrm{C}$ would result.

It should be noted that increased gate width will result in lower thermal resistance due to the larger area between the device channel and the heat sink. The thermal resistance will scale inversely with gate width. It should also be noted that $\mathrm{SiC}$ devices have demonstrated operation at temperatures exceeding $350^{\circ} \mathrm{C}$ without significant degradation. In fact, $\mathrm{SiC}$ devices often demonstrate increased currents at elevated temperatures. This is thought to be due to increased activation at the higher temperatures which compensates for the decreased charge transport characteristics.

The RF performance of the SiC MESFET as a function of temperature is indicated in Fig. 14. The RF performance is calculated for device thermal resistances of $0^{\circ} \mathrm{C} / \mathrm{W}$, $5^{\circ} \mathrm{C} / \mathrm{W}$, and $10^{\circ} \mathrm{C} / \mathrm{W}$. The dissipated dc energy causes a temperature rise in the conducting channel and, since charge carrier transport varies inversely with temperature, reduced mobility and carrier velocity result. The degraded charge carrier transport produces a reduced channel current and a corresponding degradation in RF performance. For a thermal resistance of $10^{\circ} \mathrm{C} / \mathrm{W}$ the $\mathrm{RF}$ power, maximum PAE, and linear gain are reduced by about $1 \mathrm{~dB}, 5$ percentage points, and $2.5 \mathrm{~dB}$, respectively.

The frequency performance of the devices was also examined. Frequency performance scales directly with saturation velocity and, since diamond and $\mathrm{SiC}$ have a higher saturation velocity than $\mathrm{GaAs}$, devices fabricated from these materials may be expected to operate at higher frequencies. The results of the calculations are shown in Fig. 15. This figure presents a comparison of the one $\mathrm{db}$ compressed RF power for GaAs, SiC, and diamond MESFET's as a function of frequency. The devices are redesigned and scaled for several frequencies to determine the curve. The performance of the $\mathrm{GaAs}$ devices are both experimental and calculated. That is, the model accurately predicts the performance obtained experimentally. The experimental results represent the state-of-the-art for GaAs MESFET's. The diamond and $\mathrm{SiC}$ device results were determined using

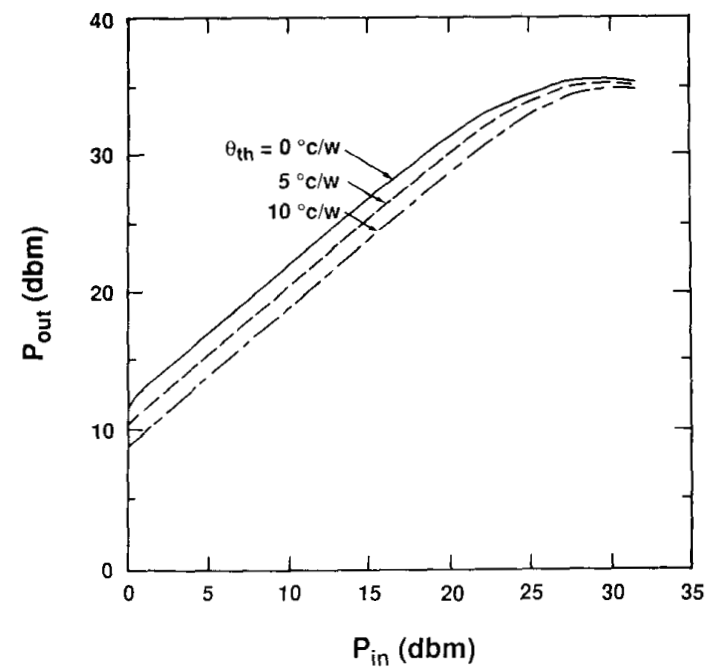

Fig. 14(a). RF output power versus input power for an SiC MESFET for various values of thermal resistance $\left(F=10 \mathrm{GHz}, L_{g}=1 \mu \mathrm{m}, W=1\right.$ $\mathrm{mm}, V_{d s}=40 \mathrm{~V}$, Class A).

the simulator. The calculations predict that at $100 \mathrm{GHz}$ about $1 \mathrm{~W}$ and $300 \mathrm{~mW}$ of RF power can potentially by obtained from diamond and SiC MESFET's, respectively. This performance is significantly better than possible with GaAs MESFET's.

\section{B. IMPATT Diodes}

The IMPATT diode has proven to be a useful device for the generation and amplification of RF energy from the microwave to the high mm-wave spectrum. Although in recent years the GaAs MESFET has taken over many of the systems applications in the microwave spectrum, IMPATT's are still used at mm-wave frequencies. The basic structure for a double-drift IMPATT diode is shown in Fig. 16. The device consists of a $p-n$ junction, sandwiched between two low doped "drift" regions. In operation, the device is biased into avalanche breakdown of the p-n junction. The electron and hole densities are driven by the electric field and travel in opposite directions through the corresponding drift regions to the device contacts. The avalanche process produces approximately a $90^{\circ}$ phase shift in the RF current relative to the RF voltage. The delay through the drift regions causes an additional inductive phase delay which, when added to that due to the avalanche process, results in a total delay exceeding $90^{\circ}$, thereby generating a negative resistance. When placed in a resonant circuit, the device oscillates. The double-drift structure is generally employed for high frequency applications since it operates basically as two back-to-back diodes. Device impedance levels are increased, thereby permitting larger area devices and higher output power to be obtained. A disadvantage of the double-drift structure is that the most significant dc power dissipation occurs in the avalanche 


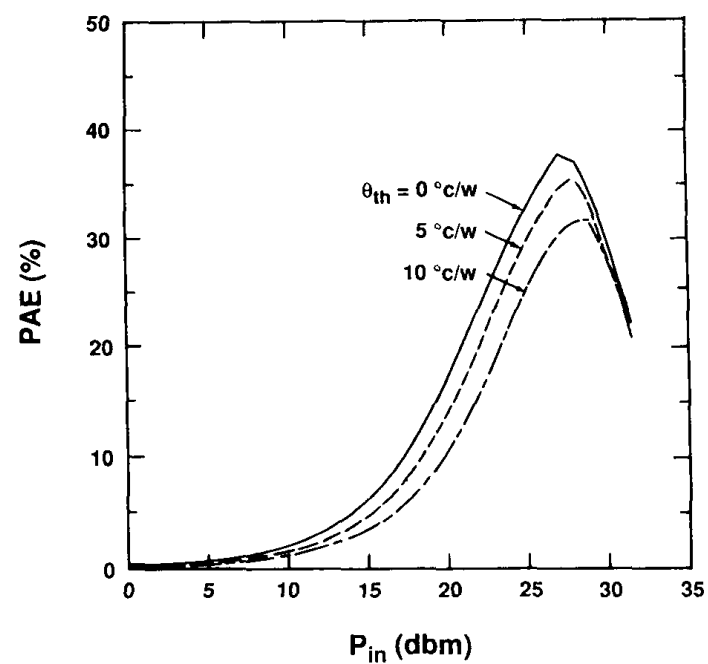

Fig. 14(b). Power-added efficiency versus input power for an SiC MESFET for various values of thermal resistance $\left(F=10 \mathrm{GHz}, L_{g}=1\right.$ $\mu \mathrm{m}, W=1 \mathrm{~mm}, V_{d s}=40 \mathrm{~V}$, Class A).

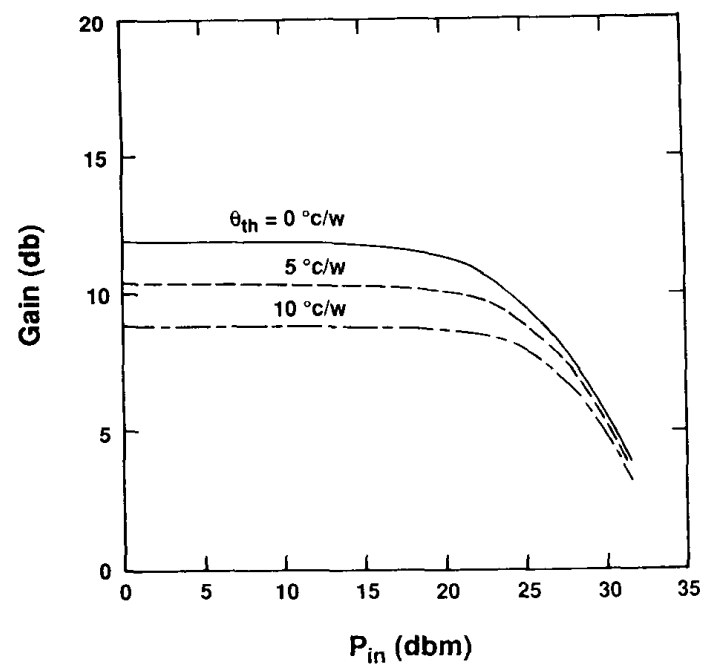

Fig. 14(c). Gain versus input power for an SiC MESFET for various values of thermal resistance $\left(F=10 \mathrm{GHz}, L_{g}=1 \mu \mathrm{m}, W=1 \mathrm{~mm}\right.$, $V_{d s}=40 \mathrm{~V}$, Class A)

region which is located inside the device. The problem is alleviated for mm-wave devices due to thin drift regions, which scale inversely with frequency.

When properly designed, the device will operate with the electric field within the device above that required to achieve charge carrier velocity saturation. The low field mobility is only important in that it determines if velocity saturation conditions can be achieved and is also fundamental in determining the parasitic resistances due to

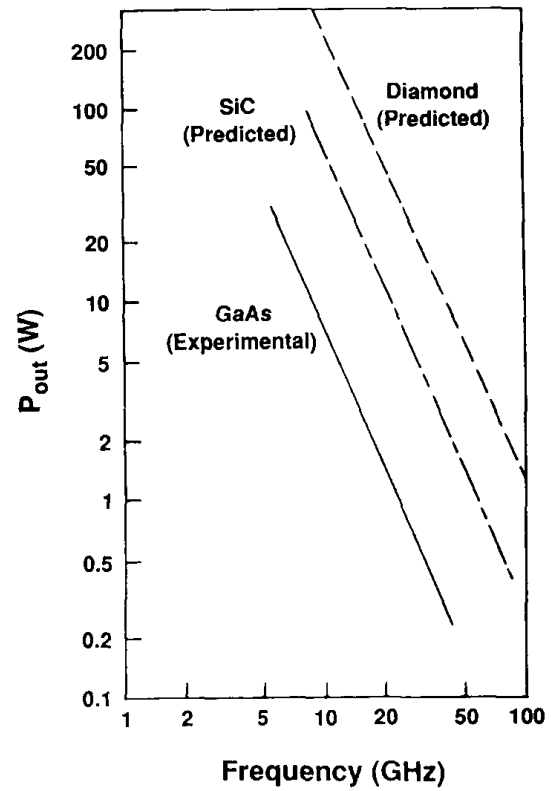

Fig. 15. RF power performance versus frequency for diamond, $\mathrm{SiC}$, and GaAs MESFET's.

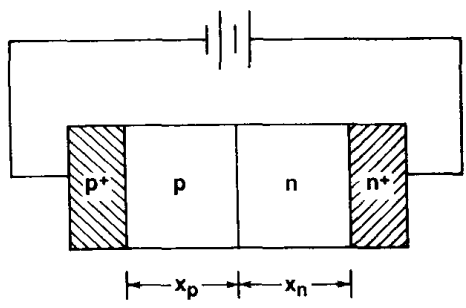

Fig. 16. Double-drift IMPATT diode structure.

the necessary bulk semiconductor and contact regions. If charge carrier mobility is too low, the semiconductor may reach dielectric breakdown conditions before the saturation field can be achieved.

IMPATT diode structures in $\mathrm{Si}, \mathrm{InP}, \mathrm{GaAs}$, and diamond were designed [98]. The various diodes were optimized by adjusting dopant levels and layer thicknesses until a peak dc to RF conversion efficiency for each diode at each frequency of interest was obtained. Operation at 35, 44, 60, and $94 \mathrm{GHz}$ was considered. All diodes were operated at the same current density for each frequency. Bias current density scales with frequency and for this study the bias current densities are $10,12,20$, and $40 \mathrm{kA} / \mathrm{cm}^{2}$ for the indicated frequencies. The design parameters for the diamond IMPATT diodes are listed in Table 4 along with the calculated breakdown voltages.

The RF output power as a function of frequency calculated for the diamond IMPATT diodes are compared in Fig. 17 to experimental data for IMPATT diodes fabricated from 
Table 4 Diamond IMPATT Diode Design Parameters

\begin{tabular}{cccccc}
\hline Frequency $(\mathrm{GHz})$ & $\mathrm{N}_{\mathrm{a}}\left(\mathrm{cm}^{-3}\right)$ & $\mathrm{N}_{\mathrm{d}}\left(\mathrm{cm}^{-3}\right)$ & $\mathrm{x}_{\mathrm{p}}(\mu \mathrm{m})$ & $\mathrm{x}_{\mathrm{n}}(\mu \mathrm{m})$ & $\mathrm{V}_{\mathrm{B}}$ \\
\hline 35 & $1.1 \times 10^{16}$ & $9.0 \times 10^{15}$ & 1.80 & 2.20 & 235 \\
44 & $1.5 \times 10^{16}$ & $1.2 \times 10^{16}$ & 1.50 & 1.80 & 208 \\
60 & $2.2 \times 10^{16}$ & $1.8 \times 10^{16}$ & 1.00 & 1.2 & 146 \\
94 & $3.6 \times 10^{16}$ & $3.1 \times 10^{16}$ & 0.80 & 0.90 & 124 \\
\hline
\end{tabular}

$\mathrm{GaAs}, \mathrm{Si}$, and InP. The numbers next to the plotted points indicate the dc-to-RF conversion efficiencies obtained. The diamond IMPATT is predicted to be capable of producing about $10 \mathrm{~W}$ RF power with $22-23 \%$ efficiency at $30-40$ $\mathrm{GHz}$. This is approximately five times the power capability of comparable Si and GaAs IMPATT's, although the conversion efficiencies are essentially equivalent. The diamond IMPATT has superior RF output power capability up to about $100 \mathrm{GHz}$. At 100 and $220 \mathrm{GHz}$, the diamond IMPATT is predicted to produce $1.5 \mathrm{~W}$ with $10 \%$ efficiency and 60 $\mathrm{mW}$ with $3 \%$ efficiency, respectively. The RF performance degrades above $100 \mathrm{GHz}$ and is approximately the same as Si IMPATT's up to about $220 \mathrm{GHz}$. The degradation in RF power of the diamond IMPATT above $100 \mathrm{GHz}$ is due to spreading of the avalanche region. That is, as the device length is reduced for higher frequency operation the avalanche region occupies an increasingly larger proportion of the total diode length, thereby degrading the device negative resistance. Optimum IMPATT operation is obtained when the avalanche region is restricted to a small portion of the total diode length. However, due to the ionization characteristics of electrons and holes in diamond it is difficult to restrict the region over which avalanche occurs. It is difficult to design IMPATT's for operation at significantly higher frequencies than indicated.

The dc-to-RF conversion efficiencies for IMPATT's fabricated from several materials are shown in Fig. 18. The conversion efficiencies for $\mathrm{Si}, \mathrm{GaAs}$, and diamond are approximately equivalent over a frequency range extending from 35 to $95 \mathrm{GHz}$, although the efficiency of the InP IMPATT is significantly higher and demonstrates less degradation with frequency.

An investigation of the RF performance of SiC IMPATT's produces results that lie between those for $\mathrm{Si}$ and diamond, in agreement with the calculations reported by Mehdi et al. [101]. At around $100 \mathrm{GHz}$, the RF power performance for a $\mathrm{SiC}$ IMPATT is essentially equivalent to that for a Si diode, but the conversion efficiency is less than obtained for the diamond device (i.e., less than approximately $10 \%$ ). Below $100 \mathrm{GHz}$ SiC IMPATT's are capable of improved RF output power compared to $\mathrm{Si}$ and GaAs devices, but have reduced RF power capability compared to diamond devices. At $20-30 \mathrm{GHz}$, a SiC IMPATT is capable of producing about 4 W RF power with a conversion efficiency of about $15-20 \%$. The high frequency performance of SiC IMPATT's is limited by relatively large series resistance due to the low carrier mobility. It will be difficult to take advantage of the double-drift structure, especially with $\alpha-\mathrm{SiC}$, due to the low hole mobility. A SiC IMPATT will probably need to be fabricated as a single drift region device to eliminate the large series resistance associated with p-type material. Low carrier mobility and the corresponding large parasitic series resistance become increasingly limiting as the device is scaled for high frequency operation. High frequency devices must have their area scaled inversely to operating wavelength, and this, in turn, enhances the magnitude of the series resistance due to aspect ratio considerations. For this reason, conversion efficiency degrades rapidly with frequency and SiC IMPATT's will, most likely, by limited to microwave applications.

\section{Bipolar Transistors}

Preliminary bipolar transistors have been reported in diamond [64], [67]. These devices were limited in RF performance by available technology. In particular, the technology required to fabricate a complex, multilayered structure such as the BJT does not presently exist. These early devices, however, indicate the bipolar devices are possible in diamond. Preliminary bipolar transistors have also been reported in $\alpha$-SiC [11] with current gains in the range of $\beta \sim 4-8$. In the work reported here, the RF performance of $\mathrm{SiC}$ bipolar transistors is investigated.

The RF power performance of bipolar transistors fabricated from $\alpha$-SiC was simulated using commercially available software [99]. The simulator permits the RF performance of devices to be investigated by the use of equivalent circuit techniques. Equivalent circuit parameter values are determined for specified bias and operating conditions and then used as input data for the model. The dc and RF circuits and the input RF conditions (input power drive and frequency) must also be supplied. The simulator returns RF output power at the fundamental and harmonics. Knowledge of the RF output power, along with the defined input power and dc bias conditions permits the RF gain and power-added efficiency to be determined.

The design of the bipolar transistor was accomplished using an iterative procedure beginning with assumed geometry and doping concentrations. For this investigation doping densities are selected based upon technologically achievable limits. That is, doping densities are limited to those possible with currently available epitaxial growth and doping technology. An initial estimate for the device geometry can be determined from impedance matching considerations, subject to distributed effects limitations. Since operation at low microwave frequency will allow large device size it is necessary to use multiple emitter 


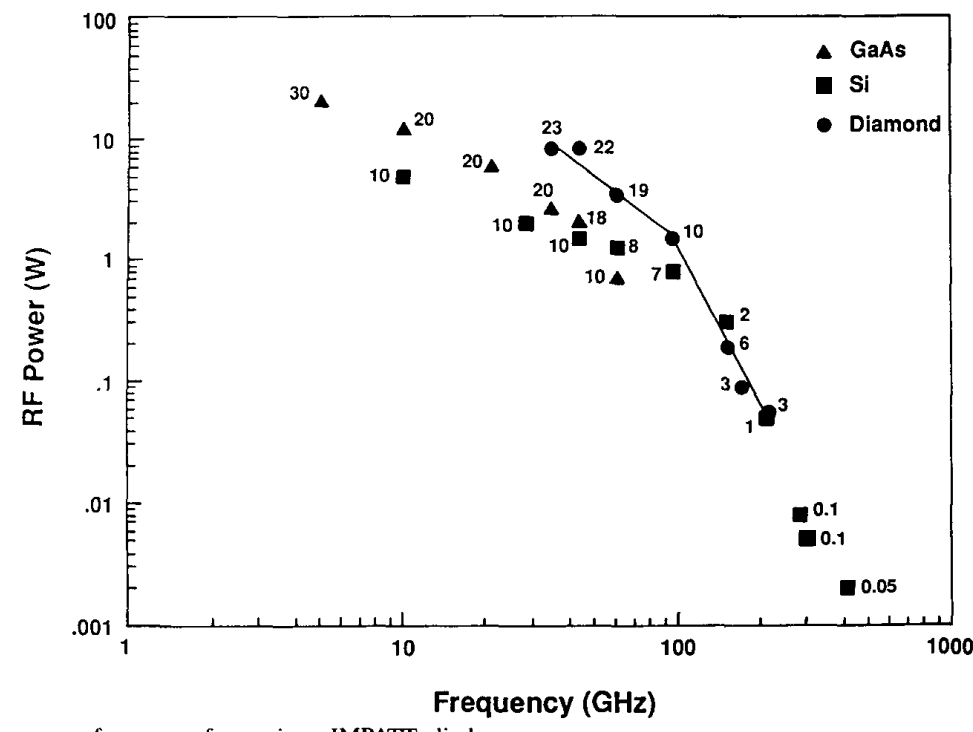

Fig. 17. RF output power versus frequency for various IMPATT diodes.

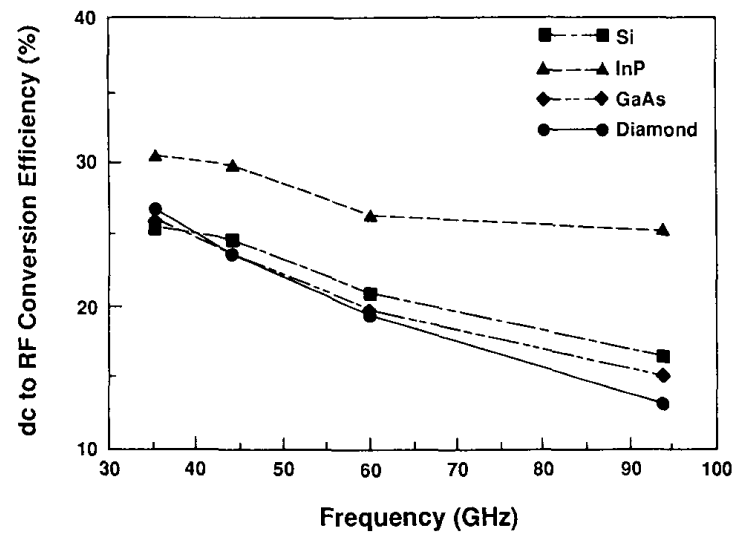

Fig. 18. Conversion efficiency versus frequency for IMPATT diodes fabricated from various semiconductors.

fingers. The length of each finger will vary according to the design frequency, but in general will be subject to the $1 / 20 \lambda$ restriction discussed in the MESFET section. The cross-section of the final device design is shown in Fig. 19 and the design parameters are listed in Table 5. The device was designed for $10 \mathrm{GHz}$ operation and has a total of eight emitter fingers. The number of emitter fingers was selected based upon impedance matching and emitter current density considerations. As the base-emitter junction area is increased the input impedance decreases. BJT's fabricated from $\mathrm{SiC}$, however, will have a relatively large base resistance and this factor will ultimately dominate the input impedance. Under these conditions the device area will be limited by emitter current density and output port impedance matching considerations. It is desirable to keep the device output impedance in the range of
25-50 $\Omega$ and the emitter current density in the range of $20-30 \mathrm{kA} / \mathrm{cm}^{2}$. The most critical design considerations were directed toward the base and collector region. Base region design issues include the conflicting effects of base region resistance and base region transit time. Collector region design issues include base-collector region capacitance (charge storage) and base-collector depletion region transit time. The base region design involves a calculation of the current gain, base resistance, and base region transittime. The current gain is calculated from consideration of minority carrier transport across the base region. In the common-base configuration, the dc current gain is defined as $\alpha_{0}$ and is given by the expression

$$
\alpha_{0}=\frac{1}{\cosh \left(\frac{W_{B}}{L_{B}}\right)+\frac{D_{p E} L_{B} N_{B}}{D_{n B} L_{E} N_{E}} \sinh \left(\frac{W_{B}}{L_{B}}\right)}
$$

where the various terms are calculated from the design dimensions listed in Table 5. Base region transit-time $\tau_{\mathbf{B}}$ is also an important factor and this parameter is generally defined in terms of the alpha cutoff frequency for the device defined as

$$
f_{\alpha}=\frac{1}{2 \pi \tau_{B}}=\frac{D_{n B}}{\pi W_{B}^{2}}
$$

The dc current gain will degrade with frequency according to the expression

$$
\alpha=\frac{\alpha_{0} e^{-j \omega \tau_{c}}}{1+j \frac{f}{f_{c}}}
$$

where the various terms are indicated in Table 6. These expressions indicate the tradeoffs between base region and base-collector region transit-times in determining the current gain for the device. 


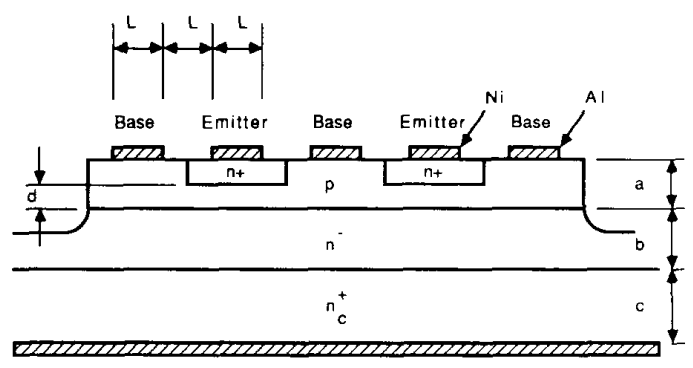

Collector

Fig. 19. Cross section of a $\mathrm{SiC}$ bipolar transistor.

Table 5 SiC Transistor Dimensions

\begin{tabular}{lc}
\hline Parameter & Dimension \\
\hline $\mathrm{L}$ & $2 \mu \mathrm{m}$ \\
$\mathrm{a}$ & $0.5 \mu \mathrm{m}$ \\
$\mathrm{b}$ & $5 \mu \mathrm{m}$ \\
$\mathrm{c}$ & $50 \mu \mathrm{m}$ \\
$\mathrm{d}$ & $0.2 \mu \mathrm{m}$ \\
$\mathrm{n}^{+}$ & $2 \times 10^{19} \mathrm{~cm}^{-3}$ \\
$\mathrm{p}$ & $3 \times 10^{18} \mathrm{~cm}^{-3}$ \\
$\mathrm{n}^{-}$ & $8 \times 10^{15} \mathrm{~cm}^{-3}$ \\
$\mathbf{n}_{\mathrm{c}}^{+}$ & $4 \times 10^{17} \mathrm{~cm}^{-3}$ \\
$\mathrm{R}_{\mathrm{c}}(\mathrm{E})$ & $5 \times 10^{-5} \Omega-\mathrm{cm}^{2}$ \\
$\mathrm{R}_{\mathrm{c}}(\mathrm{B})$ & $7 \times 10^{-4} \Omega-\mathrm{cm}^{2}$ \\
$\mathrm{R}_{\mathrm{c}}(\mathrm{C})$ & $10^{-3} \Omega-\mathrm{cm}^{2}$ \\
\hline
\end{tabular}

The base thickness is $\mathrm{W}_{\mathrm{B}}=0.2 \mu \mathrm{m}$. For this base thickness a value of $\alpha_{0}=0.894$ is obtained, which results in a commonemitter current gain of $\beta_{0}=8.4$. This is low according to $\mathrm{Si}$ BJT standards where $\alpha_{0}$ is typically greater than 0.95 and $\beta_{0}$ greater than 20 . The parameters listed in Table 5 yield a base resistance value of $29.7 \Omega$ for the 8 emitter finger device. Selection of the base region thickness and doping concentration is a critical design factor for the device. As base region thickness is reduced $\alpha_{0}$ increases and base region transit-time decrease, enhancing performance, but base resistance increases, thereby degrading performance. An increase in base region doping reduces base resistance, but decreases $\alpha_{0}$ and base-region transit-time.

Tradeoffs involved in collector region design are directed toward base-collector region capacitance, $C_{B C}$, and basecollector depletion region transit-time, $\tau_{C}$. An increase in collector doping decreases the base-collector depletion region and corresponding transit-time, but increases collector capacitance. An increased collector capacitance lowers output impedance, thereby limiting device area. The
Table 6 Element Values

\begin{tabular}{|c|c|}
\hline Parameter & Value \\
\hline No. Emitter Fingers & 8 \\
\hline Vce & $150 \mathrm{v}$ \\
\hline $\mathrm{I}_{\mathrm{ce}}$ & $1 \mathrm{~A}$ \\
\hline $\mathrm{BV}_{\mathrm{ce}}$ & $346 v$ \\
\hline $\mathbf{R}_{\mathbf{B}}$ & $29.7 \Omega$ \\
\hline $\mathbf{R}_{\mathrm{BE}}$ & $0.05 \Omega$ \\
\hline $\mathrm{C}_{\mathrm{BE}}$ & $15.92 \mathrm{pF}$ \\
\hline $\mathrm{C}_{\mathrm{BE}(0)}$ & $11.93 \mathrm{pF}$ \\
\hline $\mathrm{R}_{\mathrm{E}}$ & $2.5 \Omega$ \\
\hline $\mathrm{C}_{\mathrm{BC}}$ & $0.184 \mathrm{pF}$ \\
\hline $\mathrm{C}_{\mathrm{BC}(0)}$ & $1.5 \mathrm{pF}$ \\
\hline $\mathbf{R}_{\mathbf{B C}}$ & $250 \Omega$ \\
\hline $\mathbf{R}_{\mathrm{C}}$ & $6.4 \Omega$ \\
\hline$\alpha_{0}$ & 0.894 \\
\hline$\beta_{0}$ & 8.4 \\
\hline $\mathbf{f}_{\alpha}$ & $23.7 \mathrm{GHz}$ \\
\hline$\tau_{\mathrm{c}}$ & $23 \mathrm{pS}$ \\
\hline$\tau_{\text {(minority lifetimes) }}$ & $10 \mathrm{nS}$ \\
\hline
\end{tabular}

base-collector depletion region transit-time introduces an inductive delay that degrades RF performance.

The large-signal equivalent circuit model for the BJT used in this work is shown in the common-emitter configuration in Fig. 20. This is a standard model for the bipolar transistor and contains elements of most significance to the RF operation of the device. The calculated parameter values are listed in Table 6. Package and lead parasitic elements were added to make the simulations more physical. For this work the common-emitter configuration and class A operating conditions were chosen. Power devices can be operated either in common-emitter or common-base configurations. A common-base configuration is generally used when the device is limited in RF performance by breakdown voltage considerations. Since $\mathrm{SiC}$ has a large critical field for breakdown, collector breakdown voltage limitations are not expected to be a factor and for this reason the more desirable common-emitter configuration is selected.

The RF performance as a function of frequency for the $\mathrm{SiC} \mathrm{BJT}$ is shown in Fig. 21. At frequencies above about $1.5 \mathrm{GHz}$ the $\mathrm{RF}$ output power and gain degrade at a $-3 \mathrm{~dB} /$ octave rate. The PAE degrades rapidly with frequency and the device will not produce useful power above approximately $4 \mathrm{GHz}$. Below $1.5 \mathrm{GHz}$ the RF output power of the device is essentially constant, indicating that the device design is probably not optimum for low frequency operation. At these frequencies, the device area 


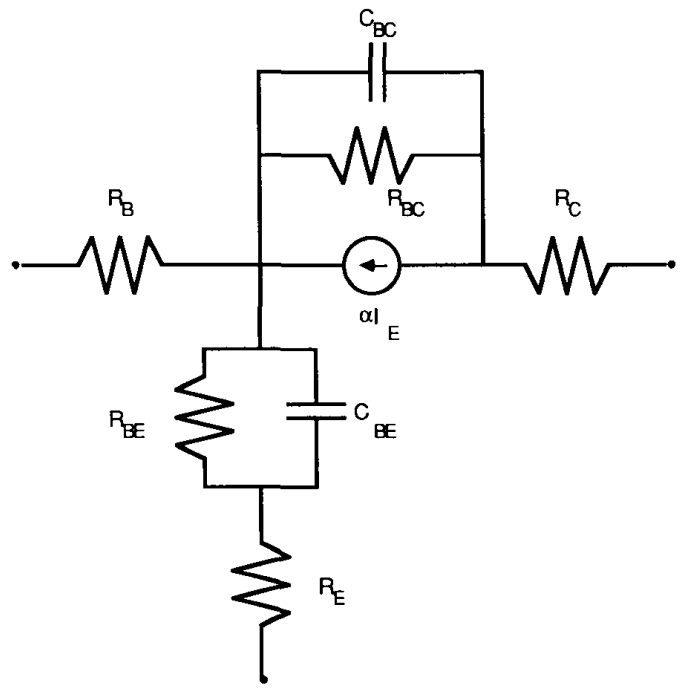

Fig. 20. Equivalent circuit for a SiC bipolar transistor.

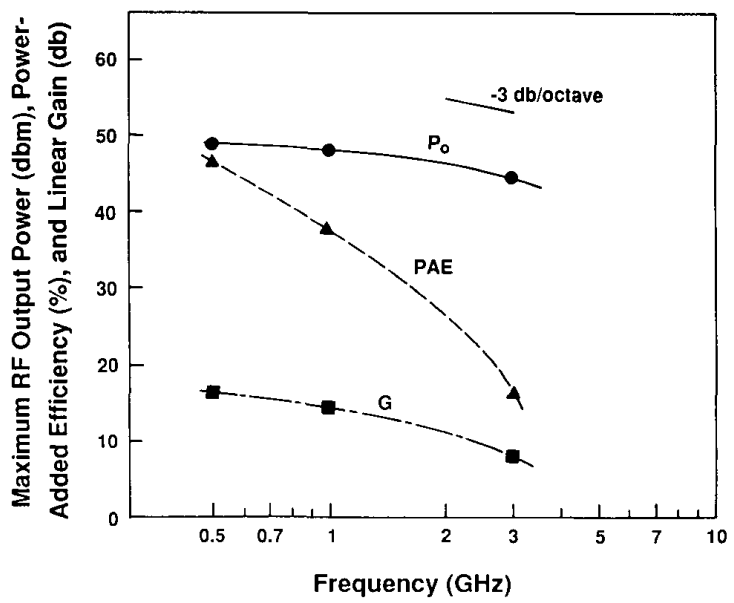

Fig. 21. RF output power versus frequency for $\mathrm{SiC}$ bipolar transistors.

could possibly be increased to increase output power. Attempts to design such a device, however, were not successful due to impedance matching problems introduced by increased collector capacitance and conductance with large area devices.

\section{SUMmaRY AND CONCLUSIONS}

The suitability of using $\mathrm{SiC}$ and diamond for fabrication of high frequency electronic devices has been investigated. The analysis consisted of theoretical calculations of the power performance of MESFET, IMPATT, and bipolar transistor device structures. Operation at microwave and millimeter-wave frequencies was considered. The MESFET is an attractive microwave device for implementation in wide bandgap semiconductor due to its simple structure, ease of fabrication and excellent RF performance. The investigation revealed that MESFET's fabricated in both $\mathrm{SiC}$ and diamond may produce microwave and mm-wave devices with superior RF power capability compared to similar devices fabricated from commonly used semiconductors such as GaAs and $\mathrm{Si}$. Diamond MESFET's are capable of producing over $200 \mathrm{~W}$ of $X$-band power as compared to about $8 \mathrm{~W}$ for GaAs MESFET's. Devices fabricated from $\mathrm{SiC}$ should perform between these limits. A $\mathrm{SiC}$ MESFET will not perform as well as a diamond device due to a larger thermal resistance, a larger dielectric constant, and a lower charge carrier mobility. Diamond MESFET's may be capable of producing approximately $1 \mathrm{~W}$ of RF power at $100 \mathrm{GHz}$. Diamond and SiC IMPATT diodes also are capable of producing improved RF power compared to $\mathrm{Si}, \mathrm{GaAs}$, and InP devices at microwave frequencies. RF performance degrades with frequency and only marginal improvements are indicated at $\mathrm{mm}$-wave frequencies. Bipolar transistors fabricated from wide bandgap material probably offer improved RF performance only at UHF and low microwave frequencies.

The realization of the predicted performance requires that significant advances be made in material growth and doping and contact technology in both $\mathrm{SiC}$ and diamond. Diamond technology, in particular, must be significantly improved if devices are to be realized. The calculations presented here assumed $n$-type diamond with activated donors of specified density. The n-type material was investigated because its properties yield the highest performance devices and the investigation was directed toward defining the ultimate performance potential of the devices. In fact, device quality n-type crystals have not yet been produced and it is not known if suitable donors for producing n-type diamond exist. Obviously, if material technology cannot be successfully developed electronic devices of significance will not be possible. These calculations do, however, indicate the potential payoff from a successful material technology. If suitable crystals can be produced, properly designed and fabricated devices have the potential to significantly improve the RF operation of high frequency devices over that available from devices fabricated from competing semiconductors. The development of diamond devices, in particular, will represent a significant improvement in the state-of-the-art. The future for $\mathrm{SiC}$ devices is more apparent. The material technology is rapidly progressing and device performance is improving. SiC diodes, LED's, and MESFET's will most likely find commercial applications. It is expected that the wide bandgap semiconductors will be useful in power applications where the combination of high carrier velocity and thermal conductance provide an advantage not available with $\mathrm{Si}$ or compound semiconductor devices. Device structures most likely to benefit from $\mathrm{SiC}$ and diamond are those that operate in velocity saturation since these devices minimize the degrading effects of low carrier mobility. 


\section{REFERENCES}

[1] R. Robertson, J. J. Fox, and A. E. Martin, "Two types of diamond," Phil. Trans. Roy. Soc., vol. A232, pp. 463-469, Mar. 1934

[2] H. Jagodzinski and H. Arnold, "The Crystal Structure of Silicon Carbide," in Silicon Carbide, A High-Temperature Semiconductor, J. R. O'Connor and J. Smiltens, Eds. New York: Pergamon, 1960, pp. 136-145.

[3] N. W. Jepps and T. F. Pagae, "Crystal growth and characterization of polytype structures," Progress in Crystal Growth and Characterization, vol. 7, p. 259, 1983.

[4] J. A. Powell, "Silicon carbide: Progress in crystal growth," Mater. Res. Soc. Symp. Proc., vol. 97, 1987.

[5] A. G. Acheson, British Patent 17911, 1892.

6] A. Lely, "Darstellung von Einkristallen von Silizium Carbid und Bekerrschung von Art and Meng der Eingebauten Verunreinigunger," Ber. Deut. Keram. Ges., vol. 32, pp. 229-231, 1955.

[7] H. J. Kim and R. F. Davis, "Physical and chemical nature of films formed on $\mathrm{Si}(100)$ surfaces subjected to $\mathrm{C}_{2} \mathrm{H}_{4}$ at elevated temperatures," J. Electrochem. Soc., vol. 134, pp. 2269-2275, Sept. 1987

[8] R. F. Davis, Z. Sitar, B. E. Williams, H. S. Kong, H. J. Kim, J. W. Palmour, J. A Edmond, J. Ryu, J. T. Glass, and C. H. Carter, "Critical evaluation of the status and the areas for future research regarding the wide bandgap semiconductors of diamond, gallium-nitride, and silicon sarbide," Mat. Sci. Eng., vol. B1, pp. 77-104, Jan. 1988.

[9] L. J. Kroko and A. G. Milnes, "Diffusion of nitrogen into silicon carbide single crystals doped with aluminum," SolidState Electron., vol. 9, pp. 1125-1134, 1966.

[10] G. Kelner, S. Binari, K. Sleger, and H. Kong, " $\beta$-SiC MES FET's and buried-gate JFET's," IEEE Electron Device Lett. vol. EDL-8, pp. 428-430, Sept. 1987.

[11] W. V. Muench, P. Hoeck, and E. Pettenpaul, "Silicon carbide field-effect and bipolar transistors," in 1977 IEEE Int. Electron Device Meeting Dig., pp. 337-339.

[12] S. Shibahara, T. Saito, S. Nishino, and H. Matsunami, "Fabrication of inversion-type n-channel MOSFET's using cubic-SiC on Si(100)," IEEE Electron Device Lett., vol. EDL-7, pp. 692-693, Dec. 1986.

[13] J. W. Bumgarner, H. S. Kong, H. J. Kim, J. W. Palmour, J. A. Edmond, J. T. Glass, and R. F. Davis, "Monocrystalline $\beta$-SiC semiconductor thin films: Epitaxial growth, doping and FET device development," in 1988 Proc. 38th Electronics Components Conf., pp. 342-349.

[14] R. F. Davis, "Epitaxial growth and doping of and device de velopment in monocrystalline $\beta$-SiC semiconductor thin films," Thin Solid Films, vol. 181, pp. 1-15, Dec. 1989.

[15] M. Yamanaka, H. Daimon, E. Sakuma, S. Misawa, and S Yoshida, "Temperature dependence of electrical properties of n- and p-type 3C-SiC," J. Appl. Phys., vol. 61, pp. 599-603, Jan. 1987.

[16] H. J. Round, "A note on carborundum," Elec. World, vol. 49, p. 309, Feb. 1907.

[17] R. W. Brander and R. P. Sutton, "Solution grown $\mathrm{SiC} p-n$ junctions," J. Phys. D: Appl. Phys., vol. 2, pp. 309-318, Mar. 1969.

[18] W. V. Muench and E. Pettenpaul, "Saturated electron drift velocity in $6 \mathrm{H}$ silicon carbide," $J$. Appl. Phys., vol. 48, pp. 4823-4825, Nov. 1977

[19] S. Yoshida, H. Daimon, M. Yamanaka, E. Sakuma, and K. Endo "Schottky-barrier field-effect transistors of 3C-SiC," J. Appl. Phys., vol. 60, pp. 2989-2991, Oct. 1986.

[20] H. Daimon, M. Yamanaka, M. Shinohara, E. Sakuma, S. Misawa, K. Endo, and S. Yoshida, "Operation of Schottky-barrier field-effect transistors of $3 \mathrm{C}-\mathrm{SiC}$ up to $400^{\circ} \mathrm{C}$," Appl. Phys. Lett., vol. 51, pp. 2106-2108, Dec. 1987.

[21] H. S. Kong, J. W. Palmour, J. T. Glass, and R. F. Davis, "Temperature dependence of the current-voltage characteristics of metal-semiconductor field-effect transistors in n-type $\beta$-SiC grown via chemical vapor deposition," Appl. Phys. Lett., vol 51, pp. 442-444, Aug. 1987.

[22] G. Kelner, S. Binari, K. Sleger, and H. Kong, " $\beta$-SiC MESFET's and buried-gate JFET's," IEEE Electron Device Lett. vol. EDL-8, pp. 428-430, Sept. 1987

[23] 97, pp. $227-232,1987$
[24] K. Furukawa, A. Hatano, A. Uemoto, Y. Fujii, K. Nakanishi, M. Shigeta, A. Suzuki, and S. Nakajima, "Insulated-gate and junction-gate FET's of CVD-grown $\beta$-SiC," IEEE Electron Device Lett., vol. EDL-8, pp. 48-49, Feb. 1987.

[25] G. Kelner, M. S. Shur, S. Binari, K. J. Sleger, and H. S. Kong, "High-transconductance $\beta$-SiC buried-gate JFET's," IEEE Trans. Electron Devices, vol. 36, pp. 1045-1049, June 1989.

[26] J. W. Palmour, " $\alpha$-SiC MESFETs" presented at the 1990 WOCSEMMAD Conf., San Francisco, CA.

[27] J. F. H. Custers, "Unusual phosphorescence of a diamond," Physica, vol. 18, pp. 489-496, Aug./Sep. 1952.

[28] C. M. Huggins and P. Cannon, "Diamond containing controllable impurity concentrations," Nature, vol. 194, pp. 829-830, June 1962.

[29] R. H. Wentorf, "Preparation of semiconducting diamonds," $J$. Chem. Phys., vol. 36, pp. 1987-1990, April, 1962.

[30] B. V. Derjaguin and D. V. Fedoseev, "The synthesis of diamond at low pressure," Sci. Amer., vol. 233, pp. 102-109, Nov, 1975.

[31] B. V. Spitsyn, L. L. Bouilov, and B. V. Derjaguin, "Vapor growth of diamond on diamond and other surfaces," $J$. Cryst. Growth, vol. 52, pp. 219-226, Apr. 1981

[32] R. Mania, L. Strobierski, and R. Pampuch, "Diamond synthesis in cool plasma," Cryst. Res. Technol., vol. 16, pp. 785-788, July 1981

[33] S. Matsumoto, Y. Sato, and M. Tsutsumi, "Growth of diamond particles from methane-hydrogen," J. Mater. Sci., vol. $17 \mathrm{pp}$ 3106-3112, Nov. 1982

[34] S. Matsumoto, Y. Sato, M. Kamo, J. Tanaka, and N. Setaka, in Proc. 7th Int. Conf. Vacuum Metallurgy, Iron and Steel Institute of Japan, Tokyo, Japan, 1982, p. 386.

[35] S. Matsumoto, Y. Matsui, "Electron microscopic observation of diamond particles grown from the vapor phase," J. Mater. Sci., vol. 18, pp. 1785-1793, June 1983

[36] K. Kobashi, K. Nishimura, Y. Kawate, and T. Horiuchi, in 34th Nat. Symp. American Vacuum Society, Anaheim, CA, Nov. 2-6, 1987.

[37] B. E. Williams, J. T. Glass, R. F. Davis, K. Kobashi, and T. Horiuchi, presented at the 34th National Symp. American Vacuum Society, Anaheim, CA, Nov. 1987, paper \#TG-WeA9,

[38] M. Kamo, Y. Sato, S. Matsumoto, and N. Setaka, "Diamond synthesis from gas phase in microwave plasma," $J$. Cryst Growth, vol. 62, pp. 642-644, Aug. 1983.

[39] Y. Mitsuda, Y. Kojima, T. Yoshida, and K. Akashi, "The growth of diamond in microwave plasma under low pressure," J. Mater. Sci., vol. 22, pp. 1557-1562, May 1987.

[40] S. Matsumoto, in Proc. 7th Int. Symp. Plasma Chemistry (Elmsford, NY), C.J. Timmermans, Ed. Eindhoven, The Netherlands: Pergamon, July 1985 , vol. 1, p. 79.

[41] S. Matsumoto, "Chemical vapor deposition of diamond in RF glow discharge," J. Mater. Sci. Lett., vol. 4, pp. 600-602, May 1985 .

[42] A. Sawabe and T. Inuzuka, "Growth of diamond thin films by electron assisted chemical vapor deposition," Appl. Phys. Lett., vol. 46, pp. 146-147, Jan. 1985.

[43] _ "Growth of diamond thin films by electron-assisted chemical vapor deposition and their characterization," Thin Solid Films, vol. 137, pp. 89-99, Mar. 1986.

[44] K. Kitahama, "Synthesis of diamond by laser-induced chemical vapor deposition," Appl. Phys. Lett., vol. 49, pp. 634-635, Sept. 1986.

[45] M. Kitabatake and K. Wasa, "Growth of diamond at room temperature by an ion-beam sputter deposition under hydrogen bombardment," J. Appl. Phys., vol. 25, pp. 1693-1695, Aug. 1985.

[46] J. E. Shigley, E. Fritsch. C. M. Stockton, J. I. Koivula, C. W. Fryer, and R. E. Kane, "The gemological properties of the sumitomo gem-quality synthetic yellow diamonds," Gems and Gemology, vol. 22, pp. 192-208, 1986.

[47] S. Yazu, "Properties and applications of high pressure synthesized diamond single crystals", presented at the Diamond Technology Initiative Symp., Crystal City, VA, July 1989, paper TH9.

[48] J. E. Shigley, E. Fritsch, C. M. Stockton, J. I. Koivula, C. W. Fryer, and R. E. Kane, Gems and Gemology, vol. 23, pp. 187-206, 1987

[49] V. S. Vavilov, M. I. Guseva, E. A. Konorova, and V. F. 
Sergienko, "Investigation of the Hall Effect in p-type semiconducting diamond doped with boron by the ion implantation method," Sov. Phys.-Semicond., vol. 4, pp. 12-16, July 1970.

[50] V. S. Vavilov, M. I. Guseva, E. A. Konorova, and V. F. Sergienko, "Investigation during isochronous multstage annealing of the electrical conductivity of semiconducting $n$ - and p-type diamonds prepared by the ion implantation method," Sov. Phys.-Semicond., vol. 4, pp. 6-11, July 1970.

[51] V.S. Vavilov, M. A. Gukasya, M. I. Guseva, T. A. Karatygia and E. A. Konorova, "Some electrical properties of diamond doped by implantation of boron ion," Sov. Phys.-Semicond., vol. 8 , pp. $471-473$, Oct. 1974 .

[52] J. F. Prins, "Activation of boron-dopant atoms in ion-implanted diamonds," Phys. Rev. B, vol 38, pp. 5576-5584, Sept. 1988.

[53] _ "Improved activation of boron-doped atoms implanted into diamond," Nuclear Instrum. Methods in Physics Research, vol. B35, pp. $484-487,1988$.

[54] _ "Fermi-dirac statistics and the nature of the compensating donors in boron-doped diamond layers," Phys. Rev. B, vol. 39, pp. 3764-3770, Feb. 1989

[55] V. S. Vavilov, M. A. Gukasya, M. I. Guseva, T. A. Karatygia, and E. A. Konorova, "Conductivity of diamond doped by implantation of phosphorus ions," Sov. Phys.-Semicond., vol. 9, pp. 962-964, 1976.

[56] V. S. Vavilov, E. A. Konorova, E. B. Stepanova, and E. M. Trukhan, "Infrared photoconductivity of diamond doped by implanting lithium ions," Sov. Phys. Semicond., vol. 13, pp. 604-606, May 1979.

[57] _ , "Electrical properties of diamond doped by implantation of lithium ion," Sov. Phys.-Semicond., vol. 13, pp. 635-638, June 1979.

[58] V. S. Vavilov, M. A. Gukasya, E A. Konorova and Y. U. Milyutin, "Implantation of antimony ions into diamond," Sov. Phys.-Semicond., vol. 6, pp. 1998-2002, June 1973.

[59] N. Fujimori, T. Imai and A. Doi, "Characterization of conducting diamond films," Vacuum, vol. 36, no. 1-3, pp. 99-102, 1986.

[60] K. Okano, H. Naruki, Y. Akiba, T. Kurosu, M. lida, and Y. Hirose, "Synthesis of diamond thin films having semiconductor properties," Japan. J. Appl. Phys., vol. 27, pp. L173-L175, Feb. 1988.

[61] V. K. Bazhenov, I. M. Bikulin, and A. G. Gontar, "Synthetic diamonds in electronics (review)," Sov. Phys.-Semicond., vol. 19, pp. 829-841, Aug. 1985.

[62] A. S. Brown, "Diamonds shine brightly in aerospace's future," Aerospace America, pp. 12-15, Nov. 1987.

[63] G. B. Rodger and F. A. Raal, "Semiconducting diamonds as thermistors" Rev. Sci Instrum, vol 31, pp. 663-664, 1960.

[64] J. F. Prins, "Bipolar transistor action in implanted diamond," Appl. Phys. Lett., vol. 41, pp. 950-952, Nov. 1982.

[65] G. H. Glover, "The C-V characteristics of Schottky Barriers on laboratory grown semiconducting diamonds," Solid-State Electron., vol. 16, pp. 973-983, 1973.

[66] L. F. Vereshchagin, K. K. Demidov, O. G. Revin, and V. N. Slesarev, "Thermistor made of p-type synthetic diamond," Sov. Phys.-Semicond., vol. 8, pp. 1581-1582, June 1975.

[67] M. W. Geis, D. D. Rathman, D. J. Ehrlich, R. A. Murphy, and W. T. Lindley, "High-temperature point-contact transistors and Schottky diodes on synthetic boron-doped diamond," IEEE Electron Device Lett vol. EDL-8, pp. 341-343, Aug. 1987.

[68] G. S. Gildenblat, S. A. Grot, C. R. Wronski, A. R. Badzian, T. Badzian, and R. Messier, "Electrical characteristics of Schottky diodes fabricated using plasma assisted chemical vapor deposited diamond films," Appl. Phys. Lett., vol. 53, pp. 586-588, Aug 1988

[69] Y. Tzeng, T. H. Lin, J. L. Davidson, and L. S. Lan, "Fabrication and high temperature characteristics of diamond electronic devices," in 1987 University/Government/Industry Microelectronics Symp., 1987, pp. 187-190.

[70] M. I. Guseva, E. A. Konorova, Y. A. Kuznetsov, and V. F. Sergienko, "Double injection of carriers in a p-i-n structure made of implantation-doped diamond," Sov. Phys. - Semicond., vol. 12, pp. 290-293, Mar. 1978

[71] H. Shiomi, Y. Nishibayaski, and N. Fujimori, "Field-effect transistors using boron-doped diamond epitaxial films," Japan. J. of Appl. Phys., vol. 28, pp. L2153-L2154, Dec. 1989

[72] W. Tsui, M. Delfino, D. Hodul, M. Riaziat, L. Y. Ching, G. Reynolds, and C. B. Cooper, "Diamond MESFET using ultrashallow RTP boron doping," IEEE Electron Device Lett., vol. 12, pp. 157-159, Apr. 1991.

[73] A. T. Collins, "Diamond electronic devices-A critical appraisal," Semicond. Sci. Technol., vol. 4, pp. 605-611, 1989.

[74] D. K. Ferry, "High-field transport in wide-bandgap semiconductors," Phys. Rev. B, vol. 12, pp. 2361-2369, Sept. 1975.

[75] C. Canali, E. Gatti, S. F. Kozlov, P. F. Manfredi, C. Manfredottti, F. Nava, and A. Quirini, "Electrical properties and performances of natural diamond nuclear radiation detectors," Nuclear Instrum. and Methods, vol. 160, pp. 73-77, 1979.

[76] M. A. Osman, G. Andrews, J. P. Kreskovsky, and H. L. Grubin, "Numerical simulation studies of semiconducting diamond electronic devices," Final Report on Contract DNA001-87-C-0250, Defense Nuclear Agency, Feb. 1989

[77] F. Nava, C. Canali, C. Jacoboni, L. Reggiani, and S. F. Kozloz, "Electron effective masses and lattice scattering in natural diamond," Solid State Commun., vol. 33, pp. 475-477, Jan. 1980

[78] W. V. Muench and E. Pettenpaul, "Saturated electron drift velocity in $6 \mathrm{H}$ silicon carbide," J. Appl. Phys., vol. 48, pp. 4823-4825, Nov. 1977

[79] M. E. Levinshtein and E. I. Radovanova, "Characterization of the drift velocity of electrons in silicon carbide subjected to strong electric fields," Sov. Phys.-Semicond., vol. 11, pp. 232-234, Feb. 1977

[80] S. Nishomo, H. Suhara, and H. Matsunami, "Reproducible preparation of cubic-SiC single crystals by chemical vapor deposition," in Extended Abstracts of the 15th Conf. Solid State Devices and Materials, Tokyo, Japan, 1983, pp. 317-320.

[81] R. A. Rudder, G. C. Hudson, M. J. Mantini, and R. B. Markunas, "Low pressure deposition of diamond films using $\mathrm{H}_{2} \mathrm{RF}$ discharges containing $\mathrm{CH}_{4}$ and $\mathrm{CO}$," presented at the Diamond Technology Initiative Symp., Crystal City, VA, 1989, p. T16.

[82] E. A. Konorova, Y. A. Kuznetsov, V. F. Sergienko, S. D. Tkachenko, A. V. Tsikunov, A. V. Spitsyn, and Y. Z. Danyushevski, "Impact ionization in semiconductor structures made of ion-implanted diamond," Sov. Phys.-Semicond., vol. 17, pp. 146-149, Feb. 1983

[83] P. Liu, R. Yen, and N. Bloembergen, "Dielectric breakdown threshold, two-photon absorption, and other optical damage mechanisms in diamond," IEEE J. Quantum Electron., vol. QE-14, pp. 574-576, Aug. 1978.

[84] G. H. Glover, "Charge multiplication in Au-SiC(6H) Schottky junctions," J. Appl. Phys., vol. 46, pp. 4842-4844, Nov. 1975.

[85] C. van Opdorp and J. Vrakking, "Avalanche breakdown in epitaxial SiC p-n junctions," J. Appl. Phys., vol. 40, pp. 2320-2322, Apr. 1969.

[86] A. P. Dmitriev, A. O. Konstantinov, D. P. Litvin, and V. I. Sankin, "Impact ionization and superlattice in 6H-SiC," Sov. Phys.-Semicond., vol. 17, pp. 686-689, June 1983.

[87] M. M. Anikin. M. E. Levinshtein, I. V. Popov, V. P. Rastegaev, A. M. Strel'chuk, and A. L. Skyrkin, "Temperature dependence of the avalanche breakdown voltage of silicon carbide $p-n$ junctions," Sov. Phys.—Semicond., vol. 22, pp. 995-998, Sept. 1988

[88] C. R. Crowell and S. M. Sze, "Temperature dependence of avalanche multiplication in semiconductors," Appl. Phys. Lett., vol. 9, pp. 242-244, Sept. 1966.

[89] J. W. Palmour, Cree Research, Triangle Park, NC, private communication.

[90] M. D. Bell and W. J. Leivo, "Rectification, photoconductivity, and photovoltaic effect in semiconducting diamond," Phys. Rev., vol. 111, pp. 1227-1231. Nov. 1958

[91] F. J. Himpsel, P. Heimann, and D. E. Eastman, "Schottky barriers on diamond (111)," Solid State Commun., vol. 36, pp. 631-633, Nov. 1980.

[92] S. A Grot G, S Gildenblat, C. W Hatfied, C R. Wronski, A. R Badzian, T. Badzian, and R. Messier, "The effect of surface treatment on the electrical properties of metal contacts to boron-doped homoepitaxial diamond film," IEEE Electron Device Lett., vol. 11, pp. 100-102, Feb. 1990.

[93] V. S. Vavilov, M. A. Gukasyan, M. I. Guseva, and E. A. Konorova, "Electrical conductivity of diamond containing implanted Li ions," Sov. Phys.-Semicond., vol. 6, pp. 741-746, Nov 1972.

[94] A. T. Collins, E. C. Lightowlers, and A. W. S. Williams, "Formation of electric contacts on insulating and semiconduct- 
ing diamonds," Diamond Res. (Suppl. Ind. Diamond Rev.), pp. $19-22,1970$.

[95] K. L. Moazed, R. Nguyen, and J. R. Zeidler, "Ohmic contacts to semiconducting diamond," IEEE Electron Device Lett., vol. 9, pp. 350-351, July 1988.

[96] K. L. Moazed, J. R. Zeidler, M. J. Taylor, R. Nguyen, and C. R. Zeisse, "Electrical contacts to semiconducting diamond," in Proc. 1989 high frequency power conversion international, Naples, FL, May, 1989, pp. 117-129.

[97] M. A. Khatibzadeh and R. J. Trew, "A large-signal, analytic model for the GaAs MESFET," IEEE Trans. Microwave Theory Tech., vol. MTT-36, pp. 231-238, Feb. 1988.

[98] P. M. Mock and R. J. Trew, "RF performance characteristics of double-drift MM-wave diamond IMPATT diodes," in Proc. 1989 IEEE/Cornell Conf. Advanced Concepts in High-Speed Semiconductor Devices and Circuits, pp. 383-389.

[99] Libra (Nonlinear Microwave Device/Circuit Simulator), EEsof, Westlake Village, CA.

[100] T. Wada and J. Frey, "Physical basis of short-channel MESFET operation," IEEE Trans. Electron Devices, vol. ED-26, pp. 476-489, Apr. 1979.

[101] I. Mehdi, G. I. Haddad, and R. K. Mains, "Microwave and millimeter-wave power generation in silicon carbide avalanche devices," J. Appl. Phys., vol. 64, pp. 1533-1540, Aug. 1988.

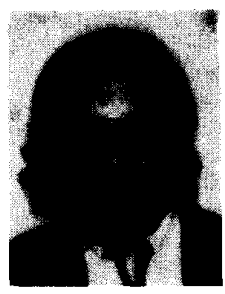

Robert J. Trew (Fellow, IEEE) received the $\mathrm{Ph}$. D. degree in electrical engineering from the University of Michigan, Ann Arbor, in 1974.

From 1974 to 1976 he was with the Watkins-Johnson Company in Palo Alto, CA where he was involved in the design and development of various microwave solidstate components. In 1977, he joined the faculty of North Carolina State University, Raleigh, where he is currently Professor of electrical and computer engineering and Director of the High Frequency Electronics Laboratory. His research interests are in microwave/millimeter-wave solid-state device modeling, microwave device and circuit design, and high frequency experimental characterization, and parameter extraction techniques.

Dr. Trew is a member of Eta Kappa Nu, Sigma Xi, Tau Beta Pi, and the American Association for the Advancement of Science. He is also a member of the Electromagnetics Academy.

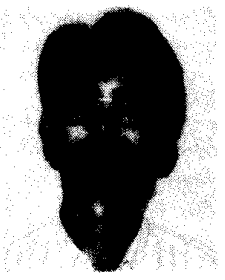

Jing-Bang Yan (Member, IEEE) received the B.S. degree in physics in 1982 from National Taiwan University, Taiwan, ROC and the M.S. degree in electrical engineering in 1987 from North Carolina State University, Raleigh. He is a Ph.D. candidate in electrical engineering and is a Research Assistant in the High Frequency Electronics Laboratory in the Electrical and Computer Engineering Department at North Carolina State University.

His research interests are in the areas of modeling, computer-added design, and characterization of microwave solid-state devices.

$\mathrm{Mr}$. Yan is a member of Eta Kappa Nu and Pi Mu Epsilon.

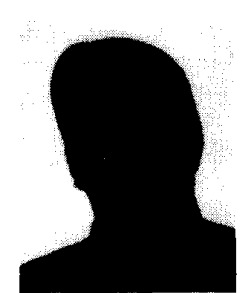

Philip M. Mock (Member, IEEE) received the B.S. degree in physics from the University of Notre Dame in 1977 and the M.S. degree in materials engineering from North Carolina State University, Raleigh in 1980 $\mathrm{He}$ is currently completing requirements for the Ph.D. degree in electrical engineering

He has been involved in GaAs FET and IMPATT development and millimeter-wave oscillator circuit design. 